\title{
凝聚体及其在人造细胞领域中的应用
}

\author{
间琳任永硕王雪靖穆鞾* 韩晓军* \\ (哈尔滨工业大学 城市水资源与水环境国家重点实验室 化工与化学学院 哈尔滨 150001)
}

\begin{abstract}
摘要 生命起源问题一直受到科研工作者的广泛关注, 合成生物学家致力于构建较为简单且在原始地球条件下合理的 隔室体系来模拟原始细胞. 凝聚体是聚合物间静电相互作用所产生的的相分离体系, 是一种可能的原始细胞结构, 广 泛应用于人造细胞的构建. 同时, 目前很多研究发现这种凝聚体在细胞内构成多种亚细胞器结构, 因此对于凝聚体作 为人造细胞器的研究也开始兴起. 作者详细综述了凝聚体的形成机理、特性和分类, 并且针对凝聚体作为人造细胞器 和人造细胞的研究进行了总结, 归纳概括了该领域发展仍需解决的科学问题, 并对该领域的发展进行了展望.
\end{abstract}

关键词＼cjkstart凝聚体；人造细胞；液液相分离；静电相互作用；人造细胞器；群体行为

\section{Coacervate and Its Application in the Field of Artificial Cells}

Yan, Lin Ren, Yongshuo Wang, Xuejing Mu, Wei* Han, Xiaojun*

(State Key Laboratory of Urban Water Resource and Environment, School of Chemistry and Chemical Engineering, Harbin Institute of Technology, Harbin 150001)

\begin{abstract}
The origin of life attracts more and more attentions of researchers. Synthetic biologists are devoting to construct a simple and rational system which can exist in primitive earth. Coacervate is a phase separation system which is formed by the interactions of polyelectrolyte. It's a rational protocell model. So far, coacervate has been found to present as membraneless organelles in natural cells. Therefore, the construction of coacervate as artificial organelles is emerging. The formation mechanism, characteristics and categories of coacervate are reviewed in this paper. Additionally, the applications of coacervate as protocell and artificial organelles are summarized. The existing scientific problems and the future development directions are provided at the end of this paper.
\end{abstract}

Keywords coacervate; artificial cells; liquid/liquid phase separation; electrostatic interaction; artificial organelle; collective behavior

\section{1 引言}

液液相分离(liquid/liquid phase separation, LLPS)是 大分子水溶液中常见的现象, 多种生物大分子 ${ }^{[1]}$ 或聚合 物 ${ }^{[2,3]}$ 的混合都能发生这种现象. 凝聚体是 LLPS 体系的 一种, 其中依赖聚合物之间静电相互作用形成的复凝聚 体得到广泛关注, 最早的复凝聚体系为阿拉伯胶-明 胶 ${ }^{[4]}$. 复凝聚发生在带正电和带负电的聚合物之间, 通 过凝聚作用形成凝聚相和连续相, 凝聚相富含这两种聚 合物, 连续相主要是水及少量的聚合物. 除了这种静电 作用形成的复凝聚体之外, 还有一种被称为简单凝聚体 的凝聚体, 它们通过简单凝聚过程实现. 在简单凝聚过 程中, 通过添加盐或去溶剂化物质(诱导剂)导致单一聚 合物脱水而形成凝聚体, 例如将 $\mathrm{Na}_{2} \mathrm{SO}_{4}$ 溶液或乙醇溶 液加入到明胶中可以导致明胶凝聚而形成简单凝聚体. 由于生物内的 LLPS 多为复凝聚现象, 所以本综述只关 注复凝聚体的研究进展.
在细胞生物学的发展过程中, 人们发现细胞内部并 不是均匀分布的, 而是包含许多具有不同组成和物理特 性的独特区域和隔室 ${ }^{[5-7]}$. 这些区域包括有膜细胞器 ${ }^{[8]}$ (如线粒体、内质网等)和无膜细胞器(如核糖体 ${ }^{[9]}$ ), 它们 在细胞内部起着定位、隔离和创建局部物理微环境的功 能 ${ }^{[5,7,8]}$. 越来越多的证据表明, 液液相分离是细胞中无 膜细胞器形成的基础 ${ }^{[10-13]}$. 液液相分离使细胞中存在独 特区域和隔室，如细胞核中的核仁(Nucleolus) ${ }^{[14]}$ 、卡哈 尔体(Cajal bodies) ${ }^{[15]}$, 以及细胞质中的应激颗粒(Stress granules $)^{[16]}$ 和 $\mathrm{P}$ 颗粒 $(\mathrm{P} \text { body })^{[17]}$ 等. 无膜细胞器通常富 含蛋白质 ${ }^{[18,19]}$ 和 RNA ${ }^{[20,21]}$, 它们一般通过复凝聚作用生 成液滴状的凝聚体. 凝聚体液滴具有内部分子拥挤、介 电常数低于周围的水连续相、可富集蛋白质、提高反应 速度、隔离有毒分子等特点 ${ }^{[1,22]}$.

人造细胞是一种简化的细胞模型. 利用自下而上的 方法构建人造细胞, 用来模仿真实细胞的某些特定功 能 ${ }^{[23,24]}$, 有助于深入理解细胞的运行机制. 以脂肪

*E-mail: muwei@hit.edu.cn; hanxiaojun@hit.edu.cn

Received June 20, 2020; published August 5, 2020.

Project supported by the National Natural Science Foundation of China (Nos. 21773050, 21929401) and the Natural Science Foundation of Heilongjiang Province for Distinguished Young Scholars (No. JC2018003).

项目受国家自然科学基金(Nos. 21773050, 21929401)和黑龙江省杰出青年科学基金(No. JC2018003)资助. 
酸 ${ }^{[25,26]}$ 、磷脂 ${ }^{[27-35]}$ 和其他两亲性聚合物 ${ }^{[36,37]}$ 为基础的人 造细胞模型已经在多方面取得了显著的研究成果, 与此 同时, 无膜的凝聚体结构也很早就被用于原始生命起源 的研究. 这种无膜的凝聚体结构是原始细胞的代表, 而 原始细胞属于人造细胞的一种. Oparin ${ }^{[38]}$ 在生命科学中 普及了凝聚作用, 并提出生命起源于凝聚体的观点, 使 人们开始关注凝聚体在模拟人造细胞方面的研究意义. 有学者 ${ }^{[7]}$ 认为在原始地球时, 还原性气氛、光照和闪电 生成的有机物溶解在原始海洋中, 可能会浓缩形成凝聚 体, 因此人们认为凝聚体可能是原始生命最初的形 态 ${ }^{[39]}$. 凝聚本身很容易制备且具有选择渗透性, 可以成 为人造细胞的研究模型, 而且凝聚状态本身也可作为细 胞内的亚细胞器结构, 模拟细胞内细胞器功能. 本综述 从静电相互作用的凝聚体出发, 总结归纳了凝聚体的形 成机理、特性和分类, 并详细阐述了凝聚体在人造细胞 器和人造细胞领域的研究进展.

\section{2 凝聚体的特征与分类}

\section{1 凝聚体的形成机理与稳定性}

\subsection{1 凝聚体的形成机理}

一般来说, 凝聚体是由聚阳离子和聚阴离子之间的 静电相互作用发生复凝聚形成的(图 1a), 可以从热力学 角度解释凝聚发生的原因. Voorn-Overbeek ${ }^{[40]}$ 理论认为 凝聚是静电相互作用驱动的自发过程, 并将凝聚解释为 带电大分子聚集形成的静电力与使体系分散的熵增之 间的竞争. Voorn-Overbeek 模型表明, 对聚电解质复合 物形成的凝聚体包括两个步骤: 第一步是在少量大分子 中形成初始水溶性复合物, 该复合物是由摘驱动的, 是 复合作用的主要驱动力; 第二步是将初始复合物重新排 列为凝聚相, 这是由于复合物中聚合物链之间或溶液中 其他自由链与复合物中聚合物链之间发生交换反应所 致, 该步骤的驱动力是结构熵的增加, 其远小于第一步 的驱动力. 此外, 不仅静电相互作用会影响凝聚, 氢键、 范德华力和疏水作用也会影响凝聚体的形成, 比如 Kim 等 ${ }^{[41]}$ 首次发现两种带正电荷的聚电解质(重组贻贝足蛋 白 (Rmfp-1) 与聚(2-(三甲基氨基)乙基甲基丙烯酸酯 (MADQUAT)) 可以发生配位和凝聚, Rmfp-1 是一种富含 $\pi$ 键的聚合物, MADQUAT 是富含阳离子的聚电解质, 阳离子和 $\pi$ 键可通过静电引力、极化等相互作用, 形成 阳离子 $-\pi$ 键, 它比水溶液中带相反电荷的聚合物之间的 静电吸引力更强.

\subsection{2 影响凝聚体稳定性的因素}

凝聚体的形成过程十分复杂, 其稳定性受到多种因 素的影响 ${ }^{[40,42-44]}$. 影响凝聚的外部条件包括 $\mathrm{pH}$ 、盐离子 浓度 ${ }^{[45]}$ 、盐离子类型 ${ }^{[46]}$ 和温度 (如热敏聚合物 ${ }^{[43]}$ ). 如图 $1 \mathrm{~b}$ 所示, $\mathrm{pH}$ 、温度和离子强度等条件都存在一个临界点, 当条件超过临界点后, 无论怎样改变聚合物的浓度, 都
不会有凝聚体生成. 而当外部条件处于临界点以下时, 聚合物的浓度成为影响凝聚体生成的内在因素，过高和 过低的浓度都不利于凝聚体的生成. 当体系处于两相区 时, 如处在 $K_{1}$ 和 $K_{2}$ 连线上任意一点, 凝聚作用发生后, 连续相(水相)应该处于 $K_{1}$ 点状态, 而凝聚体内状态则为 $K_{2}$ 所示.

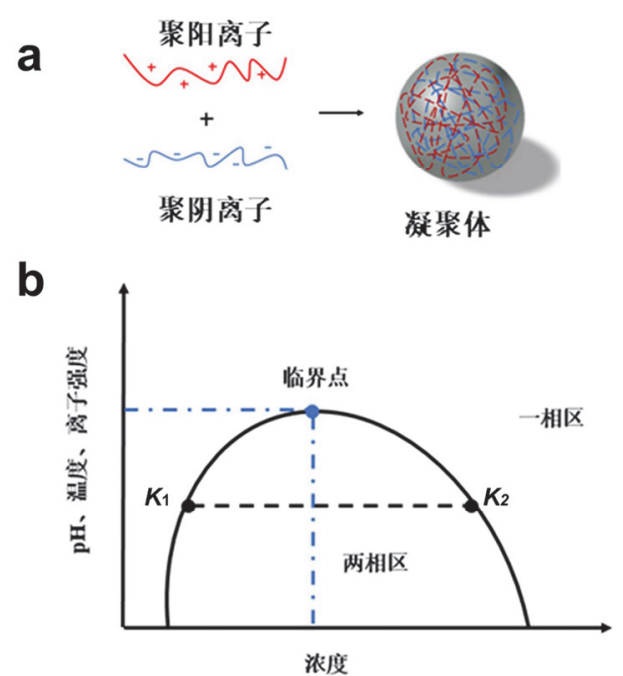

图 1 凝聚体的形成机理及相图. (a) 聚阳离子和聚阴离子通过静电相 互作用生成凝聚体; (b)浓度、 $\mathrm{pH}$ 、温度和离子强度对凝聚体生成的影 响的相图

Figure 1 The formation mechanism and phase diagram of coacervates. (a) Polycations and polyanions generate coacervates through electrostatic interaction; (b) phase diagram about the effect of concentration, $\mathrm{pH}$, temperature and ionic strength on coacervates formation

盐溶液浓度对于凝聚体生成有两个方面的影响，一 是盐溶液可以促进构成凝聚体的两种聚电解质的溶解 进而促进凝聚体的生成; 二是盐溶液中离子作为聚电解 质的抗衡离子, 能够与聚电解质结合, 屏蔽其所带电荷, 使得电荷密度降低，从而抑制凝聚体的生成. 低盐条件 下，前者占主导，因此随盐溶液的浓度的增加凝聚体生 成量增多, 而高盐溶液中, 后者为主要影响因素, 从而 盐溶液浓度的增加会对凝聚体的生成起到抑制作用. Schuster 等 ${ }^{[47]}$ 研究了自凝聚蛋白(RGG-RGG)浓度和 $\mathrm{NaCl}$ 浓度的相图, 得到较高浓度的 $\mathrm{NaCl}$ 对复凝聚过程 有抑制作用, 并且随着蛋白质浓度的升高临界 $\mathrm{NaCl}$ 浓 度越高, 即高浓度的复凝聚原料可以稳定凝聚体(图 2a). 温度也是影响凝聚体稳定的一重大因素, Deng 等 ${ }^{[48]}$ 通 过调节温度控制凝聚体的可逆生成和解离, 囊泡中的凝 聚体随温度降低而分解, 升高温度后凝聚体又重新形成 (图 2b, 囊泡与凝聚体都呈绿色苂光, 尺寸较大的圆代 表囊泡, 圆中的绿色亮点代表凝聚体). 此外, 溶液的 $\mathrm{pH}$ 会影响分子的电荷密度, $\mathrm{pH}$ 的改变可以使弱聚电解 质电荷密度降低到原来的 $70 \% \sim 90 \%{ }^{[42]}$, 进而影响凝聚 体的形态. 弱聚阳离子在高 $\mathrm{pH}$ 下电荷密度低, 而在低 $\mathrm{pH}$ 条件下显示出更加高的电荷密度，而聚阴离子则具 有相反的行为. Koga 等 ${ }^{[49]}$ 构建了聚赖氨酸和腺嘌呤核 
a

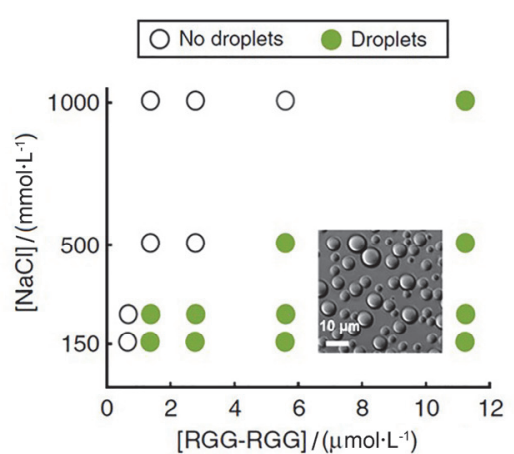

b
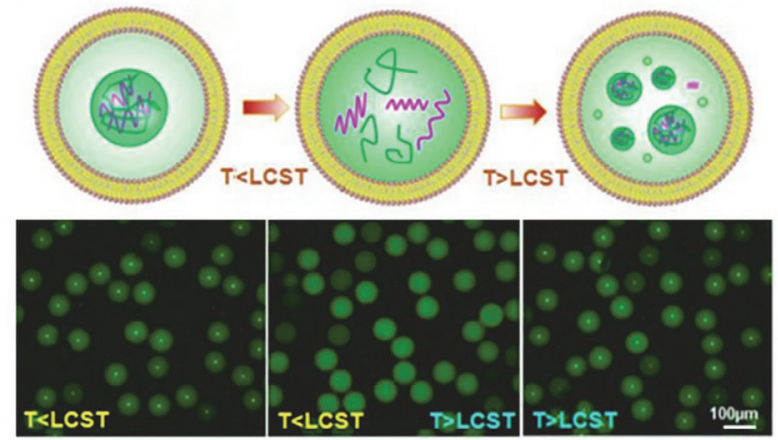

C
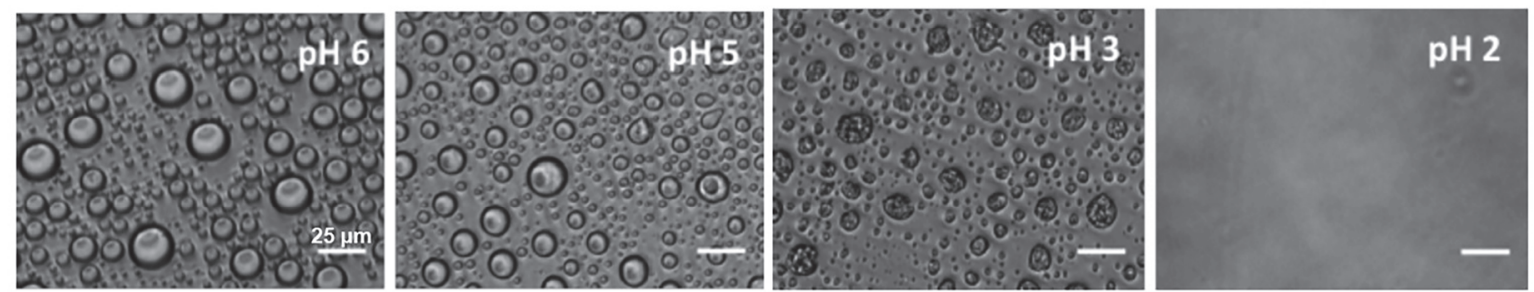

图 2 离子强度、温度和 $\mathrm{pH}$ 对凝聚体的影响. (a) (RGG-RGG)蛋白质浓度和盐溶液浓度对于凝聚体形成影响的相图 ${ }^{[47]}$; (b)脂质体内的凝聚体受温 度调控可逆凝聚的原理示意(上)图及对应的苂光显微镜照片(下) ${ }^{[48]}$; (c) 通过降低 $\mathrm{pH}$ 值使得 PGlu/Ply 凝聚体降解的明场显微镜图 ${ }^{[50]}$.

Figure 2 The effect of ionic strength, temperature and $\mathrm{pH}$ on the coacervates. (a) Phase diagram of (RGG-RGG) protein and salt concentration on coacervates formation $^{[4]}$. Copyright 2018, Springer Nature. (b) Schematic illustration of the reversible assembly and disassembly of coacervates in liposomes with temperature changeing (top) and the corresponding fluorescence images (bottom) ${ }^{[48]}$. Copyright 2017, Wiley-VCH. (c) Brightfield micrographs of PGlu/Ply coacervates disassembly by lowering $\mathrm{pH}^{[50]}$. Copyright 2014, American Chemical Society.

苷三磷酸(ATP)组成的凝聚体体系, 通过向溶液中通入 $\mathrm{CO}_{2}$ 和 $\mathrm{NH}_{3}$ 来调节溶液的 $\mathrm{pH}$, 使得凝聚体反复形成. Black 等 ${ }^{[00]}$ 通过降低 $\mathrm{pH}$ 值使聚谷氨酸(PGlu)/聚赖氨酸 (Ply)凝聚体分解从而释放内部包裹的物质(图 2c). 此外, 其他能改变原料电荷分布的过程如蛋白质的修饰等都 可以影响凝聚体的稳定性. Aumiller 等 ${ }^{[1]}$ 发现蛋白质的 磷酸化状态可以调节其电荷密度, 从而控制凝聚体液滴 形成的过程. 他们设计具有可磷酸化丝氨酸的阳离子肽 段(序列 $2 \times R R A S L$ ) 作为聚阳离子, 聚尿嘧啶核苷酸 (poly U) 作为聚阴离子, $\lambda$ 蛋白磷酸酶 (LPP)使肽链去磷 酸化, 产生带正电荷的肽, 随后可以与 poly U 形成凝聚 体. 之后可以通过蛋白激酶 A (PKA) 来使肽链磷酸化, 降低肽链的正电荷数目, 从而导致凝聚体分解. 该工作 将凝聚体的可逆生成与细胞内重要生物过程相关联, 提 供了一种生物体内调控的思路.

凝聚体的界面张力随聚电解质链长的增加而增加, 随盐溶液浓度的增加而降低, 具有高电荷密度的强聚电 解质比弱聚电解质具有更高的界面张力 ${ }^{[52]}$, 因此也更 易形成球形夜滴. Frankel 等 ${ }^{[53]}$ 发现高电荷密度的 RNA 在聚(烯丙基胺)(PAH) 和 ATP 凝聚体体系中能够取代 ATP, 这是由于 RNA 的电荷密度比 ATP 高, 更易形成凝 聚体液滴.

\section{2 凝聚体的分类}

复凝聚是聚电解质通过静电相互作用发生凝聚的 物理过程. 根据复凝聚体的凝聚层相数可以将凝聚体分 为单相凝聚体和多相凝聚体. 目前研究的复凝聚体大多
数只能够形成单一的凝聚相(图 3a, 3c), 即单相凝聚体. 但是最近几年, 研究者们发现在一些特殊情况下, 形成 凝聚体的物质超过两种时，也可能形成一种凝聚体包裹 凝聚体的多相凝聚体结构(图 3b, 3d).
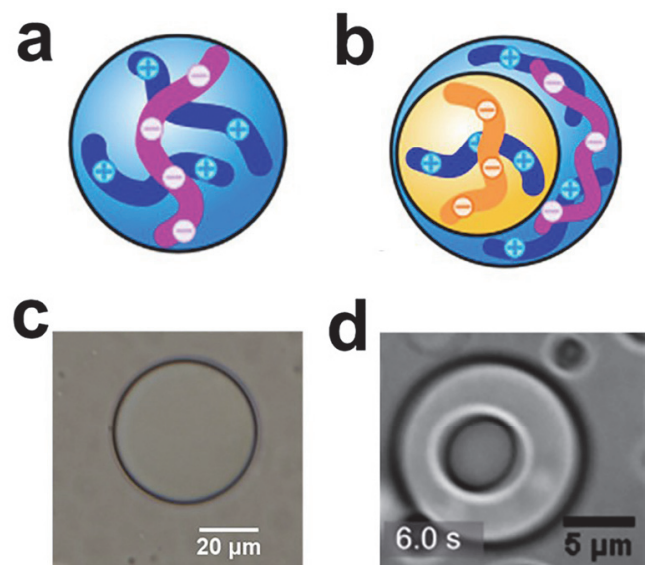

图 3 单凝聚相与多凝聚相凝聚体. (a)单凝聚相凝聚体的结构示意 图 ${ }^{[73]}$; (b)二凝聚相凝聚体的结构示意图 ${ }^{[73]}$; (c) 聚二烯丙基二甲基氯 化铵(PDDA)和 ATP 两种原料构成的单凝聚相凝聚体; (d) PGlu/PAH/ PDDA 三种原料构成的二凝聚相凝聚体, 内部为 PGlu/PAH 核心, 外 部凝聚层为 $\mathrm{PGlu} / \mathrm{PDDA}^{[73]}$

Figure 3 Coacervates with one condensed phase and two coexisting condensed phases. (a) Schematic illustration of coacervates with one condensed phase ${ }^{[73]}$; (b) Schematic illustration of coacervates with two coexisting condensed phases ${ }^{[73]}$; (c) One condensed phase coacervates composed of PDDA and ATP; (d) Two coexisting condensed phases coacervates composed of poly glutamic acid (PGlu)/PAH inner core surrounded by a PGlu/PDDA shell ${ }^{[73]}$. Copyright 2020, American Chemical Society. https://pubs.acs.org/doi/abs/10.1021/jacs.9b11468 


\subsection{1 单相凝聚体}

单相凝聚体简单来说就是仅有一层凝聚相的复凝 聚体结构. 单相凝聚体是最普遍的复凝聚结构, 很多聚 电解质之间的组合都能够形成单相凝聚体, 在这里, 为 了更加清晰地将已报道的单相凝聚体体系进行介绍, 主 要按照形成单相凝聚体的物质种类又对单相凝聚体进 行了分类. 形成凝聚体的原料众多, 既包括生物大分子 如蛋白质、核酸、多糖, 也包括非生物聚电解质(如聚苯 乙烯磺酸盐(PSS))和小分子的核苷酸(如 ATP). 早期的 凝聚体都是由高分子量的聚合物组成, 而 Koga 等 ${ }^{[49]}$ 首 次利用 ATP 这类小分子物质作为原料合成了凝聚体结 构. 在这里我们根据形成凝聚体的原料不同, 将凝聚体 的种类分为非生物分子凝聚体, 生物分子和非生物分子 形成的凝聚体, 生物分子凝聚体与包含小分子的凝聚体 这 4 个体系. 此外, 还有部分聚合物同时具有正电荷区
域和负电荷区域，使得其自身能够在一定条件下发生复 凝聚作用，形成一种特殊的自凝聚体. 关于上述所提到 的 5 类单相凝聚体体系, 在表 1 中给出了相关内容的工 作总结.

非生物分子凝聚体形成的主要原料为非蛋白质、核 酸和多糖等其他种类的聚电解质. 目前，应用比较多的 阳离子聚合物主要有聚甲基丙烯酸 $N, N$-二甲基氨基乙 酯(PDMAEMA)、PAH、聚醚酰亚胺(PEI)、聚(2-甲基丙 烯酰氧基)乙基三甲基氯化铵(PMETAC)等，阴离子聚合 物有聚丙烯酸(PAA)、PDDA、甲基丙烯酸 3-磺酸丙酯 钾盐(PSPM)等. 已经用该类非生物分子体系实现很多

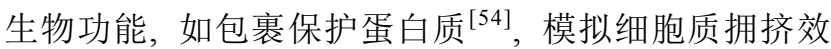
应 $^{[55]}$ 等. 此外, 部分非生物分子也成功与生物分子形成 凝聚体. Obermeyer 等 ${ }^{[56]}$ 使用琥珀酸酐修饰蛋白质 $(\alpha$ 胰 凝乳蛋白酶原、肌红蛋白和核糖核酸酶(RNase)和溶菌

表 1 凝聚体的分类及应用

Table 1 Classification and application of coacervates

\begin{tabular}{|c|c|c|c|c|c|}
\hline \multicolumn{2}{|c|}{ 类型 } & 原料 & 组分/凝聚相 & 生成特征和应用 & 参考文献 \\
\hline \multirow{18}{*}{$\begin{array}{l}\text { 单 } \\
\text { 相 } \\
\text { 凝 } \\
\text { 聚 } \\
\text { 体 }\end{array}$} & \multirow{6}{*}{$\begin{array}{l}\text { 非生物 } \\
\text { 分子凝 } \\
\text { 聚体 }\end{array}$} & PAA/PAH & $2 / 1$ & PAA/PAH 凝聚体保护 BSA 免受极端 $\mathrm{pH}$ 和尿素的变性破坏 & [54] \\
\hline & & PDDA/PAA & $2 / 1$ & 在十二烷油相中, 使用二氧化硅纳米粒子稳定凝聚体 & [89] \\
\hline & & $\begin{array}{l}\text { PAA/PDMAEMA/PAH、 } \\
\text { PAA/PDMAEMA/PEI }\end{array}$ & $3 / 1 、 3 / 1$ & $\begin{array}{l}\text { 三元凝聚体相较于基础的二元凝聚体系统，具有更好的盐溶 } \\
\text { 液浓度稳定性 }\end{array}$ & [45] \\
\hline & & PDMAEMA/PAA & $2 / 1$ & $\begin{array}{l}\text { 通过优化使得凝聚体内部溶菌酶浓度达到细胞质中蛋白质浓 } \\
\text { 度 }(200 \mathrm{~g} / \mathrm{L})\end{array}$ & [55] \\
\hline & & $\begin{array}{l}\text { PAA- } g \text {-PNIPAM/PDMAPAA- } g \text { - } \\
\text { PNIPAM }\end{array}$ & $2 / 1$ & $\begin{array}{l}\text { 聚合物含有热响应性聚( } N \text {-异丙基丙烯酰胺)(PNIPAM)支链, } \\
\text { 室温形成凝聚体, 升温后转变为水凝胶 }\end{array}$ & [90] \\
\hline & & PMETAC/PSPM & $2 / 1$ & $\begin{array}{l}\text { 复凝聚层与水相界面的表面张力值通过 AFM 探针测得为 } 100 \\
\mu \mathrm{N} / \mathrm{m} \text { 数量级, 且会随着盐浓度的升高而降低 }\end{array}$ & [52] \\
\hline & \multirow{6}{*}{$\begin{array}{c}\text { 生物分 } \\
\text { 子和非 } \\
\text { 生物分 } \\
\text { 子形成 } \\
\text { 的凝聚 } \\
\text { 体 }\end{array}$} & $\begin{array}{l}\alpha \text { 胰凝乳蛋白酶原/ } \\
\text { PDMAEMA、 } \alpha \text { 胰凝乳蛋白 } \\
\text { 酶原/qP4VP、肌红蛋白/ } \\
\text { PDMAEMA、肌红蛋白/ } \\
\text { qP4VP、RNase/PDMAEMA、 } \\
\text { RNase/qP4VP、溶菌酶/ } \\
\text { PDMAEMA、溶菌酶/qP4VP }\end{array}$ & 均为 $2 / 1$ & $\begin{array}{l}\text { 琥珀酸䣶修饰的蛋白质 }(\alpha \text { 胰凝乳蛋白酶原、肌红蛋白、RNase、 } \\
\text { 溶菌酶), 增大了负电残基比例, 能够与阳离子聚电解质 } \\
\text { (PDMAEMA 和 P4VP)形成凝聚体 }\end{array}$ & [56] \\
\hline & & GFP/qP4VP、GFP/PEI & $2 / 1 、 2 / 1$ & $\begin{array}{l}\text { 设计了离子标签肽段, 位于 GFP 的 C 端, 与阳离子聚电解质形 } \\
\text { 成凝聚体, 并且对 GFP 苂光强度影响较小 }\end{array}$ & [57] \\
\hline & & $\begin{array}{l}\text { 超电荷 GFP/PAA、超电荷 } \\
\text { GFP/PSS }\end{array}$ & $2 / 1,2 / 1$ & $\begin{array}{l}\text { 超电荷 GFP(正电)与阴离子聚合形成凝聚体, 具有更好的 } \mathrm{pH} \\
\text { 和盐浓度稳定性 }\end{array}$ & [58] \\
\hline & & $\begin{array}{l}\text { 超电荷 GFP/qP4VP、超电荷 } \\
\text { GFP/PEI }\end{array}$ & $2 / 1,2 / 1$ & $\begin{array}{l}\text { 超电荷 GFP(负电)与阳离子聚合形成凝聚体, 具有更好的 } \mathrm{pH} \\
\text { 和盐浓度稳定性 }\end{array}$ & [57] \\
\hline & & $\begin{array}{l}N \text {-[(芴-9-基甲氧基)羰基]- } D \text {-丙 } \\
\text { 氨酸- } D \text { 丙氨酸 } \\
\text { (Fmoc-AA)/PDDA }\end{array}$ & $2 / 1$ & $\begin{array}{l}\text { 结构自适应的二肽 Fmoc-AA 与 PDDA 形成受 } \mathrm{pH} \text { 响应形成含 } \\
\text { PDDA 的二肽水凝胶 }\end{array}$ & [74] \\
\hline & & 羧甲基葡聚糖/PDDA & $2 / 1$ & $\begin{array}{l}\text { 负电性的叶绿体通过静电相互作用包裹在凝聚体内, 实现光 } \\
\text { 合作用中的光反应电子传递 }\end{array}$ & [91] \\
\hline & \multirow{6}{*}{$\begin{array}{c}\text { 蛋白质 } \\
\text { (或多 } \\
\text { 肽)与蛋 } \\
\text { 白质(或 } \\
\text { 多肽)凝 } \\
\text { 聚体 }\end{array}$} & BLG/明胶 B & $2 / 1$ & $\begin{array}{l}\text { 当 }[\text { 明胶 B }]:[\mathrm{BLG}]<1 \text { 时, 形成凝聚体, 而 }[\text { 明胶 B]：[BLG]> } \\
1 \text { 时, 逐渐形成凝胶相 }\end{array}$ & [60] \\
\hline & & $\mathrm{BSA} /$ 明胶 $\mathrm{B}^{[78]}$ & $2 / 1$ & $\begin{array}{l}{[\mathrm{BSA}] \text { 和 }[\text { 明胶 B]的比值决定了常温下的凝聚状态, 并且凝聚 }} \\
\text { 体加热到 } 32{ }^{\circ} \mathrm{C} \text { 以上时会产生不可逆的浑浊凝胶 }\end{array}$ & [61] \\
\hline & & 卵清蛋白/溶菌酶 & $2 / 1$ & $\begin{array}{l}\text { 卵清蛋白和溶菌酶未折叠形成液态凝聚体，而未折叠的两种 } \\
\text { 蛋白质形成固相 }\end{array}$ & [18] \\
\hline & & 超电荷 GFP/PLy & $2 / 1$ & $\begin{array}{l}\text { 设计了离子标签肽段, 位于 GFP 的 C 端, 使 GFP 所带负电荷 } \\
\text { 增加. 这种 “超电荷 GFP” 可与 PLy 生成凝聚体 } \\
\text { 对于同手性多肽, 带相反电荷的侧链不仅有静电相互作用, 而 }\end{array}$ & [57] \\
\hline & & $D, L$-PLy $/ D, L$-PGlu & $4 / 1$ & $\begin{array}{l}\text { 且会产生氢键作用, 使凝聚体产生固态性质; 但是当存在外消 } \\
\text { 旋多肽时, 凝聚体为液相 }\end{array}$ & [62] \\
\hline & & BSA/PLy/PGlu & $3 / 1$ & BSA 与 PLy 形成正电中间体，再与 PGlu 发生凝聚 & [50] \\
\hline
\end{tabular}




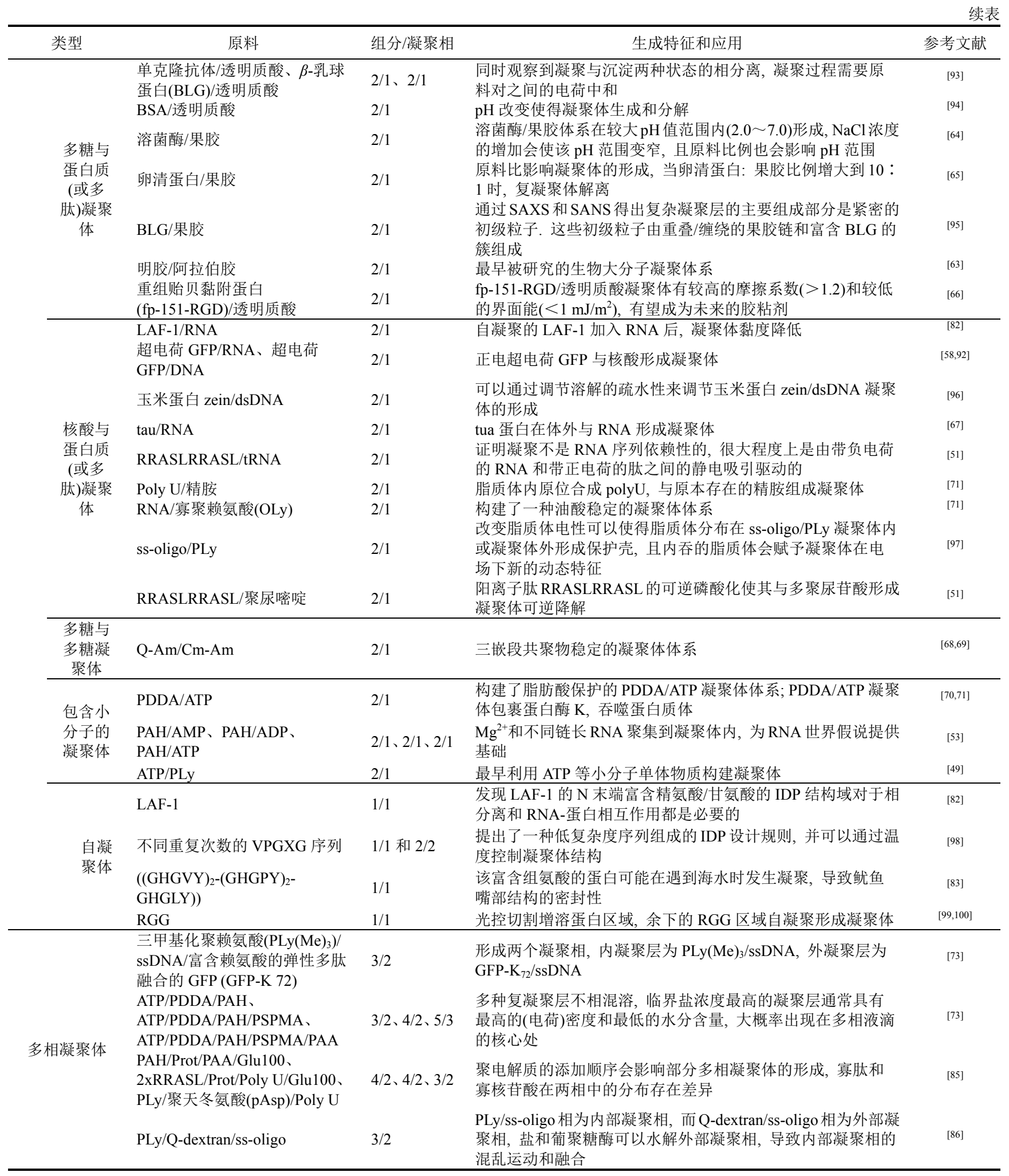

表中 “/”指和的关系, 如 PDDA/ATP 指 PDDA 和 ATP 可以生成凝聚体.

酶), 增加蛋白质负电残基比例, 能够与阳离子聚电解 质 (PDMAEMA、聚 (4-乙烯基 $N$-甲基吡啶碘化 物)(qP4VP))发生凝聚. 类似的, 以绿色荧光蛋白(GFP) 为主的超电荷蛋白质也能够满足较高的电荷密度, 与非 生物的聚电解质形成凝聚体 ${ }^{[57,58]}$. 更加复杂的 $\mathrm{pH}$ 响应
的凝聚体向水凝胶的转变也可通过结构自适应的二肽 Fmoc-AA 和 PDDA 的凝聚实现.

凝聚现象的研究在生物材料中还是更加广泛的, 主 要包括蛋白质(多肽)、多糖和核酸等大分子物质. 根据 具体原料的种类，可细分为蛋白质(或多肽)与蛋白质(或 
多肽) 凝聚体、多糖与蛋白质 (或多肽) 凝聚体、核酸与蛋 白质(或多肽) 凝聚体和多糖与多糖凝聚体. 以蛋白质为 基础的复合物质具有多种形态: 凝聚体、固态沉淀和单 分散的胶束, 这些状态受到蛋白质特性、共聚电解质特 性及整体溶液特性(如盐浓度和 $\mathrm{pH}$ )等方面的影响, 并且 具有较高的应用价值 ${ }^{[59]}$. 蛋白质(或多肽)之间形成的凝 聚体的凝聚状态在改变原料比例时, 会形成凝胶结 构 $^{[60]}$, 同时也存在温度的不可逆性凝胶化作用 ${ }^{[61]}$. 与此 同时, 蛋白质(或多肽)的折叠情况 ${ }^{[18]}$ 与手性 ${ }^{[62]}$ 等都可能 影响凝聚相的生成. 多糖与蛋白质(或多肽)凝聚体系中 被最早研究的凝聚组分是明胶/阿拉伯胶 ${ }^{[63]}$. 随着研究 的深入, 很多体系的特征如 $\mathrm{pH}^{[64]}$ 、盐离子浓度 ${ }^{[64,65]}$ 等方 面的影响已明确. 该体系也展现出了在食品封装和胶粘 剂等方面的潜在应用价值 ${ }^{[65,66]}$. 核酸与蛋白质(或多肽) 凝聚体系是对生物体内亚细胞器结构最好的模拟, 研究 一般涉及多种生物过程, 如阿尔兹海默症相关蛋白 tua 与 RNA 可在体外形成凝聚体 ${ }^{[67]}$, 肽链磷酸化对肽链与 核酸之间凝聚的影响 ${ }^{[51]}$ 等. 除了蛋白质为基础的凝聚 作用研究之外, 其他种类的生物分子凝聚现象较少, 季 铵化直链淀粉 (Q-Am)/羧甲基化直链淀粉(Cm-Am)也可 形成凝聚体, 而且 Mason 等 ${ }^{[68,69]}$ 设计了一个三嵌段共聚 物来稳定该凝聚体体系.

小分子凝聚体体系, 主要指包含 ATP、二磷酸腺苷 (ADP)、单磷酸腺苷(AMP)等小分子单体的凝聚体体系. 小分子体系中 ATP 等小分子的抗衡离子一般为非生物 分子, 如 $\mathrm{PDDA}^{[70,71]}, \mathrm{PAH}^{[72]}$ 等, 生物分子则包括 $\mathrm{Ply}{ }^{[49]}$. 此外 ATP还参与了一些使用多种凝聚原料的体系, 参与 多相凝聚体的形成 ${ }^{[73]}$.

活细胞内发生凝聚的蛋白质大部分都是固有无序 蛋白(Intrinsically Disordered Proteins, IDP) ${ }^{[74-77]}$ 或含有固 有无序区 (Intrinsically Disordered Protein Regions, IDR $)^{[78-80]}$ 的蛋白. 自凝聚体以细胞内的 $\operatorname{IDP}^{[74-77]}$ 或含 $\mathrm{IDR}^{[78-80]}$ 的蛋白为主, IDP 或 IDR 在结构上并不稳定, 因 为缺乏二级或三级结构, 其主要成分是无序的氨基酸序 列. 这些氨基酸序列复杂度较低, 多是一些重复的极性 氨基酸 ${ }^{[63]}$, 如组氨酸. 在某些 IDP 自凝聚系统中, 添加 聚阴离子 $\mathrm{RNA}^{[81]}$ 可以在更大范围的溶液条件下形成液 滴, 这表明复凝聚起主导作用. 因此, 可以证明 IDP 或 IDR 对生物体内凝聚体的形成具有重要的意义. 这种自 凝聚现象在生物体内也是十分普遍, 如秀丽隐杆线虫胚 胎中 P 颗粒内的 LAF-1 部分对相分离起重要的作用 ${ }^{[82]}$, 鱿鱼嘴中的 $\left.\left((\mathrm{GHGVY})_{2}-(\mathrm{GHGPY})_{2}-\mathrm{GHGLY}\right)\right)$ 可能对嘴 部密封起到重要作用 ${ }^{[83]}$. 除了生物体内的 IDP 和 IDR 自 凝聚的研究, Madinya 等 ${ }^{[84]}$ 使用矩阵转移理论, 研究了 电荷序列对于两性聚合物自凝聚的影响.

\subsection{2 多相凝聚体}

Mountain 等 ${ }^{[85}$ 基于包含两个或三个聚阴离子以及 一个、两个或三个聚阳离子的混合物体系研究了多相凝
聚体，发现这种多相凝聚体的生成与聚电解质的添加顺 序有关, 且多相凝聚体的内外分布主要是表面张力所决 定的, 表面张力较小的相层在外层, 而较大的则分布在 内层, 如在 PAH, 硫酸鱼精蛋白(Prot), PAA 和聚谷氨酸 (Glu100)的两相凝聚体体系内, PAH 和 PAA 主要分布在 内层, 而 Prot 和 Glu100 主要分布在外层, 这是因为 $\gamma_{\text {out-Glu100 }}<\gamma_{\text {Glu100-PAH }} \leqslant \gamma_{\text {out-PAH }}$ (out 代表外部溶液). 此外 聚电解质的电荷密度和链的长短也对多相凝聚体的内 外层分布具有一定的影响. Lu 等 ${ }^{[73]}$ 发现多凝聚相溶液 中不同的凝聚相性质具有区别，作者利用 3-磺酸丙基甲 基丙烯酸(PSPMA)/PDDA/PAH 形成三组分的两相凝聚 体，发现凝聚相可以富集尼罗红、绿色荧光蛋白(GFP) 及罗丹明 $\mathrm{B}$, 且两个凝聚相对溶质显示不同强度的吸收 分配能力.

多相凝聚体的动态性质也得到了深入研究. Jing 等 ${ }^{[86]}$ 使用单链寡核苷酸 (ss-oligo), 季铵化葡聚糖 (Q-dextran)和 Ply 构建了一种两相凝聚体体系, 发现通 过外加盐溶液或葡聚糖酶水解外层凝聚体, 可导致内部 隔室的运动和混合. 同时他们还在电场下研究了这种多 相凝聚体的动态性质，发现低电场下会产生与单相凝聚 体内相同的循环特性 ${ }^{[87,88]}$, 但是循环过程中内部凝聚相 的融合会使得循环发生偏斜, 高强度的电场则会直接极 化整个液滴，导致子液滴的释放. 这类层状的多相凝聚 体结构具有丰富的可调节性, 如每一相中富集的物质浓

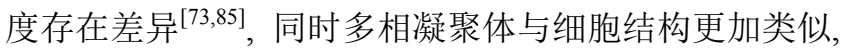
在构建人造细胞体系方面也具有不可替代的应用前景. 因此, 关于多相凝聚体的研究虽然只是刚刚开始, 却是 该领域不可忽视的研究方向.

\section{3 凝聚体在人造细胞领域的应用}

凝聚体在生物体中作为蛋白质和核酸等物质的聚 集体，能够对基因调控、RNA 加工等生命过程进行调节， 在生物体内起着十分重要的作用 ${ }^{[22]}$. 例如, 凝聚体可以 作为细胞对环境变化进行快速反应的结构(对环境中温 度、 $\mathrm{pH}$ 和离子强度等条件敏感而快速解离和生成), 凝 聚体可以浓缩生物分子从而激活生化反应(对蛋白质等 物质的富集)等. 体外的凝聚体重构已经能够轻易实现， 并且凝聚体已经用于多种生物系统 ${ }^{[101]}$. 随着人们自下 而上重构细胞研究的深入 ${ }^{[102,103]}$, 凝聚体作为无膜细胞 器的代表, 已经被用作细胞器引入人造细胞中, 甚至已 经在真实细胞内重新构建并研究其功能. 对于凝聚体人 造细胞器的研究, 不仅能够为人造细胞提供合适的实验 模型, 而且有助于理解生物微环境与凝聚体的关系, 理 解部分疾病与无膜细胞器的关系.

在人造细胞领域，目前主要使用的模型为以磷脂为 基础的脂质体囊泡 ${ }^{[104]}$. 磷脂是生物膜的主要成分, 是 生物膜形成的基础. 磷脂膜结构相对于脂肪酸等物质构 成的膜结构有较强的稳定性 ${ }^{[105]}$. 丰富的磷脂种类也为 
囊泡的表面性质提供了多种可能 ${ }^{[106,107]}$, 同时磷脂膜结 构上可以负载丰富的膜蛋白, 以赋予膜丰富的生化功 能 ${ }^{[108-110]}$. 除了这种有膜的磷脂囊泡系统外, 无膜的凝 聚体作为一种 LLPS 体系也是一种人造细胞模型, 相比 于脂质体它们则有用更好的动态性, 良好的渗透性, 并 且对于部分物质能够自发富集 ${ }^{[49,50]}$, 这为局部快速动态 的生化反应提供了良好的微环境 ${ }^{[111]}$. 同时凝聚体的制 备十分简便, 这使得凝聚体人造细胞模型受到了广泛的 关注. 以脂质体等为人造细胞, 凝聚体为人造细胞器的 复合人造细胞系统也成为研究热点. 接下来将归纳凝聚 体作为人造细胞模型和细胞器模型的研究进展, 总结凝 聚体在人造细胞领域的研究进展, 以及面临的挑战.

\section{1 凝聚体作为人造细胞器的应用研究}

细胞器是分散在细胞质内具有特定生化功能的微 隔室, 保证细胞生物体内各种生化反应的有序进行. 其 中多隔室的膜结构可以从结构上很好地模拟细胞器, 如 在聚合物囊泡中引入尺寸较小的脂质体、聚合物水凝胶 胶囊中包裹囊泡等. 但这样的体系较难模拟细胞器的功 能, 凝聚体作为生物体内的一类细胞器结构, 在体外易 合成, 且能够通过富集蛋白质和核酸等物质赋予凝聚体 一定生化功能. 因此, 以凝聚体作为人造细胞器模型的 研究得到了广泛关注. 最近已有研究在脂质体等人造细 胞中引入凝聚体 ${ }^{[89,112]}$, 在结构和功能上模拟细胞器.

目前, 在人造细胞中引入凝聚体作为人造细胞器的 主要方法包括微流控和原位合成法 ${ }^{[113]}$. 微流控技术为 人造细胞模型的构建提供了良好的手段 ${ }^{[114]}$. Deng 等 ${ }^{[48]}$ 通过微流控法在单个脂质体内包封了单分散凝聚体液 滴 (图 4a). 他们利用微流控装置制备了水包油包水 $(\mathrm{W} / \mathrm{O} / \mathrm{W})$ 双乳液结构, 将聚赖氨酸/ATP 构成的凝聚体包 封在内层水相中(图 4a1). 双乳液中的油相在外层水相 中 F68 的去润湿作用下可以形成油滴, 并最终脱离双乳 液液滴, 同时得到包有凝聚体的囊泡结构(图 4a2). Linsenmeier 等 ${ }^{[115]}$ 利用微流控法在液滴内包封了以 ATP 酶 (Dhh1)和 RNA 为原料形成的凝聚体, 并研究了无膜细 胞器的动力学特性. 微流控技术有着很高的产率与包封 率, 能够高通量地制备含有无膜细胞器的多室人造细胞 结构, 但是, 微流控技术需要较复杂的装置, 且操作难 度较大. 另外也有研究 ${ }^{[116]}$ 通过凝胶辅助溶胀方法在生 成脂质体同时包裹凝聚体.

原位合成法指凝聚体在人造细胞内原位合成的方 法. 当 ATP 等小分子物质被发现可用于凝聚体的形成 后, Deshpande 等 ${ }^{[117]}$ 使用 $\alpha$-溶血素将脂质体打孔, 溶液 中的 ATP 跨膜进入囊泡并与包封在内部的聚赖氨酸 (PLL)结合, 原位形成无膜人造细胞器结构(图 4b). 此 外, 他们在脂质体内部包封带正电的精氨酸和磷酸化酶 (PNPase), 通过打孔并外加二磷酸尿苷(UDP)、单磷酸尿 苷(UMP), 在脂质体内生成的 poly U 可与精胺形成无膜 细胞器. 通过 $\alpha$-溶血素等通道打孔的方式, 虽然能够原
位合成凝聚体，但是改变了脂质体的通透性.

凝聚体的稳定性受到多种因素影响, 如 $\mathrm{pH}$ 、离子强 度和温度等. 因此可以通过调节上述条件, 实现凝聚体 在人造细胞内的原位合成. Love 等 ${ }^{[116]}$ 在凝聚体内包裹 聚赖氨酸和 ATP, 由于聚赖氨酸的等电点为 10.5 , 因此 在 $\mathrm{pH}$ 为 11 时, 聚赖氨酸带负电, 不能与带负电的 ATP 形成凝聚体; 而调节 $\mathrm{pH}$ 到 9 时, 聚赖氨酸带正电, 能与 ATP 形成凝聚体(图 4c). 同时, 在这种凝聚体中富集了 酶并加速了底物甲酸、 $\mathrm{NAD}^{+}$的生化反应. Booth 等 ${ }^{[112]}$ 在蛋白质体中同时包封葡萄糖氧化酶(GOx)和 PDDA, 外加的 ATP 溶液可扩散进入蛋白质体中, 与 PDDA 结合 在膜内表面形成凝聚体, 当向其中加入 $\mathrm{NaCl}$ 提高了溶 液的离子强度后, 膜上的凝聚体形成液滴分散在蛋白质 体中(图 4d). 此外, 通过调节温度实现了脂质体内部凝 聚体的可逆形成 ${ }^{[48]}$. 通过改变环境条件生成凝聚体人 造细胞器的过程, 展示了人造细胞对外界环境刺激作出 的响应，具有十分重要的研究意义.

在真实细胞内构建凝聚体人造细胞器也具有十分 重要的生理意义, 因此受到了广泛关注. Shin 等 ${ }^{[118]}$ 在细 胞内表达光响应蛋白 Cry2 连接的 IDR 序列, 光刺激可 使 Cry2 解聚, 从而导致 IDR 序列自发凝聚, 并且研究了 凝聚体在细胞内的老化. Reed 等 ${ }^{[99]}$ 研究了激光调节的 IDR 序列自凝聚在人造液滴内和酵母细胞中的行为, 他 们将麦芽糖结合蛋白序列、光解蛋白序列及两段 RGG 序列重组在一起形成融合蛋白，再将其分别导入油包水 液滴和真实细胞中, 在 $405 \mathrm{~nm}$ 的激光照射下, 光解蛋白 序列可发生断裂，剩余的 RGG 蛋白序列可发生自凝聚 形成凝聚体(图 4e).

凝聚体作为细胞器可以实现一系列的生化反应, 可 以利用微流控法与原位合成法在人造细胞体系内重构 出凝聚体, 并且在光刺激下真实细胞中的凝聚体细胞器 的研究也已经实现. 但是凝聚体作为细胞器的制备以及 应用还有很大的探索空间，如包含两种原料的脂质体间 通过膜融合形成凝聚体的应用以及基因调控等生物功 能还有待实现.

\section{2 凝聚体作为人造细胞的应用研究}

人造细胞作为研究生命起源与细胞运行机制的重 要体系, 相关研究已经取得了突出成果 ${ }^{[104,119]}$. 但是目 前的人造细胞模型如脂质体、蛋白质体、聚合物囊泡等 都很难在早期地球环境下存在, 而凝聚体作为简单的依 赖静电相互作用的液液相分离体系, 很可能代表了原始 细胞最初的结构. 针对目前对于凝聚体人造细胞模型的 研究, 我们在这里将其分为个体功能与群体行为两个方 面进行总结和论述.

\subsection{1 凝聚体人造细胞的个体功能}

在原始细胞 ${ }^{[120-124]}$ 研究中, 原始地球环境下凝聚体 螯合 $\mathrm{RNA}^{[125]}$ 并实现化学性能 ${ }^{[126]}$ 对于原始细胞学说具 
a

\section{a1}

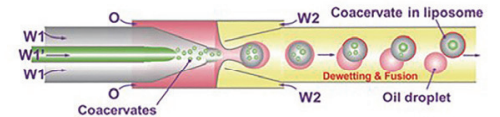

a2

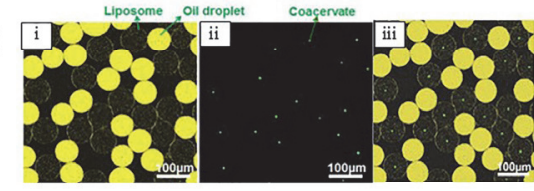

C
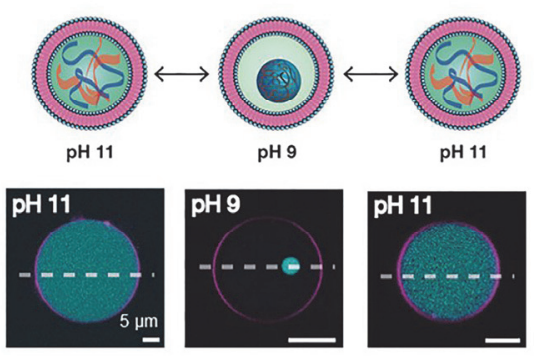

b
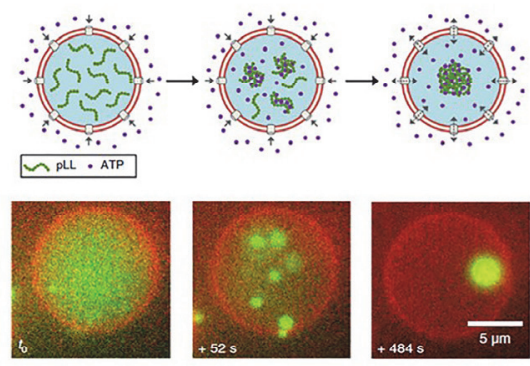

d
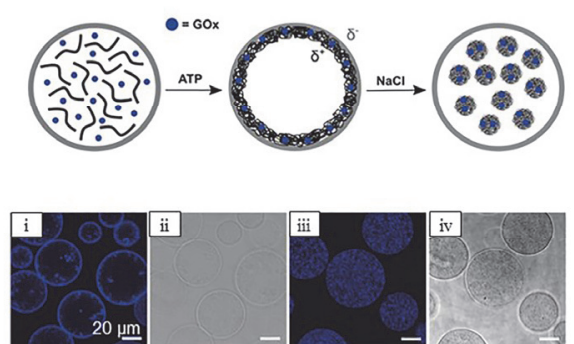

e
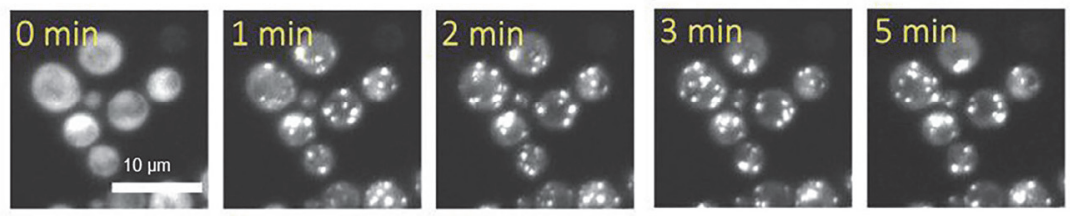

图 4 凝聚体作为人造细胞器的应用. (a)利用微流控技术制备囊泡包凝聚体的结构: (a1)微流控法示意图, (a2) (i)油滴与囊泡、(ii)凝聚体的苂光显 微镜照片, (iii)为(i)和(ii)图的叠加图 ${ }^{[48]}$; (b)利用 $\alpha$-溶血素开孔在囊泡中生成凝聚体的示意图(上)及对应荧光显微镜照片(下) ${ }^{[117]}$; (c)改变 $\mathrm{pH}$ 在囊泡 内可逆形成凝聚体的示意图(上)及对应荧光显微镜照片(下) ${ }^{[16]}$; (d)蛋白质体中形成凝聚体的示意图(上)和显微镜照片: (i、ii) 凝聚体吸附在蛋白质 体膜上, (iii、iv) 凝聚体游离在蛋白质体中 ${ }^{[112]}$; (e)光驱动的蛋白质凝聚体在酵母细胞内形成 ${ }^{[99]}$.

Figure 4 Application of coacervates as artificial organelles. (a) Coacervates in vesicles prepared by using microfluidic technology: (a1) Schematic illustration of microfluidic technology, (a2) fluorescence image of (i) oil droplets and vesicles, (ii) coacervates, (iii) the overlap of (i) and (ii) ${ }^{[48]}$. Copyright 2017, Wiley-VCH. (b) Schematic illustration of the formation of coacervates in vesicles by using $\alpha$-hemolysin pore (top) and time-lapse fluorescence images (bottom) ${ }^{[17]}$. Copyright 2019, Springer Nature. (c) Schematic showing that changing the $\mathrm{pH}$ to form coacervates reversibly in the vesicles (top) and the corresponding fluorescence images (bottom) ${ }^{[116]}$. Copyright 2020, Wiley-VCH. (d) Schematic of the formation of coacervates in proteinosomes (top) and fluorescence images: (i, ii) coacervates are adsorbed on the proteinosomes membrane, (iii, iv) coacervates are free in the proteinosomes ${ }^{[112]}$. Copyright 2019, Wiley-VCH. (e) Optically-regulated protein coacervates formed in a single yeast cell ${ }^{[99]}$. Copyright 2020 , American Chemical Society.

有一定的推动作用. RNA 与聚阳离子通过静电相互作用 形成凝聚体，这种相互作用往往会破坏 RNA 的天然结 构, 导致 RNA 的生理功能不能正常表现. 凝聚体中螯 合 RNA 被认为是基于原始地球条件形成的微区室 ${ }^{[49]}$. 早期研究并没有关注它的化学活性, 而 Drobot 等 ${ }^{[127]}$ 创 造性地证明了 RNA 酶在凝聚体中具有催化活性, 在凝 聚体中其活性增大 60 倍. 他们提取了烟草环斑病毒中 一种小的锤头状核酶(RNA, 图 5a1), 将凝聚体置于含 有核酶的裂解缓冲液中, 裂解产物羧基荧光素(FAM)在 $0 \mathrm{~min}$ 和 $900 \mathrm{~min}$ 的苂光强度变化 (图 5a2) 证明凝聚体中 发生了 RNA 对底物催化的反应. 该结果说明凝聚体作 为原始细胞模型是合理的, 该成果对 RNA 世界假说具 有一定的推动作用. 他们发现凝聚体能选择性地保留较 长的 RNA, 这可能是由于较长的 RNA 有较高的电荷密 度, 电荷密度越高则越更易形成凝聚相 ${ }^{[53]}$. Poudyal 等 ${ }^{[28]}$ 再一次证明凝聚体可以增强多种 RNA 的化学活 性, 他们在凝聚体中实现了 RNA 聚合酶催化 RNA 的转 录, 以及两种核酶、一种脱氧核酶的催化, 他们发现在
较低 $\mathrm{Mg}^{2+}$ 浓度下, RNA 聚合酶仍能行使催化功能, 完 成转录. RNA 酶的催化作用在一定程度上证明了凝聚体 作为人造原始细胞结构的合理性, 为后续研究奠定了基 础.

细胞内遗传物质的表达是一类重要的生命过程, Poudyal 等 ${ }^{[128]}$ 在凝聚体内实现了转录过程, 完成了基因 表达的第一步. Tang 等 ${ }^{[121]}$ 通过无细胞基因表达系统在 羧甲基葡聚糖/聚赖氨酸凝聚体液滴内生成了荧光蛋白 (mCherry)(图 5b), 为细胞遗传信息的表达提供了研究基 础.

凝聚体还可将某些生物成分 ${ }^{[129]}$ 吸收到隔室之中, 构建具有仿生功能的人造细胞. Kumar 等 ${ }^{[9]}$ 通过机械摚 拌将带负电的植物叶绿体螯合进入正电的 PDDA/羧甲 基葡聚糖凝聚体中(图 5c), 并引入 2,6-二氯苯酚吲哚酚 (DPIP), 成功验证了光反应的活性.

虽然凝聚体对物质的富集作用使其在人造细胞研 究方面的应用不断增加, 但是由于其固有的无膜特性, 凝聚体的不稳定性成为限制它的重要因素, 施加一定的 
外壳 ${ }^{[68,69,131,132]}$ 保护成为解决该问题的主要手段. Mason 等 ${ }^{[68,69]}$ 构建了一个三元嵌段共聚物(聚乙二醇、聚己内 酯/聚三亚甲基碳酸酯和聚谷氨酸, PEG-PCLgTMCPGlu), 阴离子共聚物能够与凝聚体(Q-Am 和 Cm-Am) 发生静电相互作用, 在凝聚体表面自组装形成一层半透 性的薄膜, 该膜能够防止凝聚体聚集并能维持凝聚体的 球形状态(图 5d). 共聚物膜结构在一定程度上能抵抗溶 液离子强度, $\mathrm{pH}$ 等物理因素的影响. 另外 Cakmak 等 ${ }^{[130]}$ 利用 Pickering 乳液模型, 凝聚体由物质的量比为 $1: 1$ 的 PDADMAC/PAA 形成. 通过调节磷脂的比例控制脂 质体的电性, 当脂质体磷脂组成为磷脂酰乙醇胺 $(\mathrm{PE}) /$
磷脂酰胆碱 $(\mathrm{PC}) /$ 磷脂酰丝氨酸 $(\mathrm{PS})=1: 2: 1$ 时, 可以 在凝聚体外表面发生自组装形成膜结构(图 5e ii), 而当 脂质体组成为 $\mathrm{PC} / \mathrm{PS}=1: 1$ 时(图 $5 \mathrm{e}$ i) 由于磷脂电性的 改变, 从而破坏凝聚体.

以凝聚体为基础的人造细胞模型可以提高多种 RNA 酶的催化活性、构建仿生细胞以及实现基因转录 和翻译等生物反应，已经能够从结构和功能上模拟人造 细胞. 同时, 对于无膜结构所带来的不稳定性, 目前也 可通过界面自组装生成膜壳结构改善. 这些研究对于原 始细胞学说具有一定的推动作用.

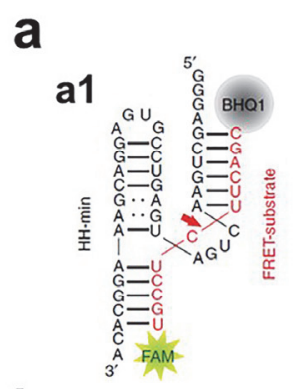

b

$1 \mathrm{~h}$

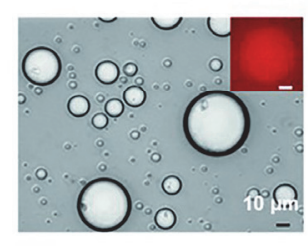

d

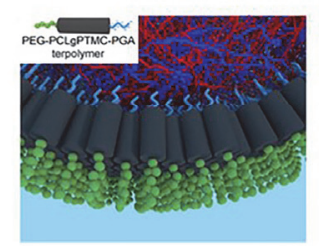

$0 \mathrm{~min}$

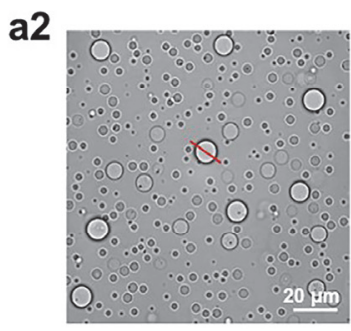

$16 \mathrm{~h}$
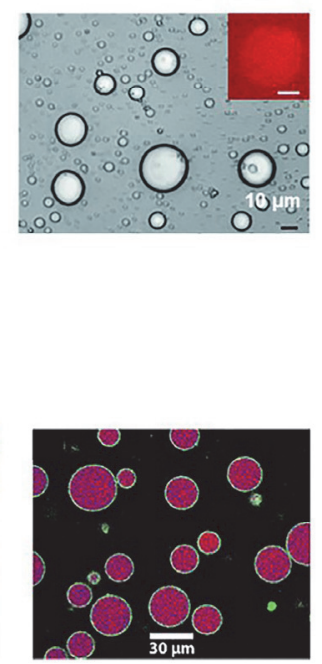

$0 \mathrm{~min}$

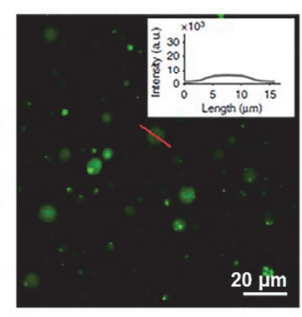

C

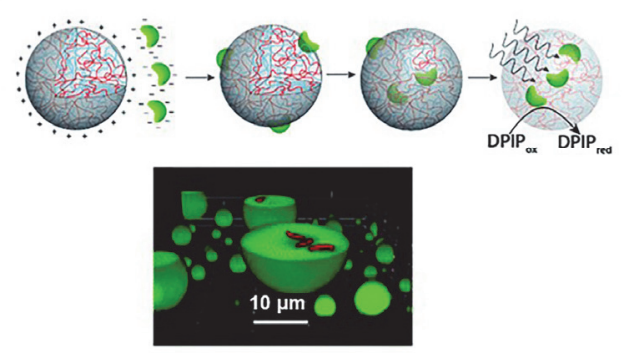

e
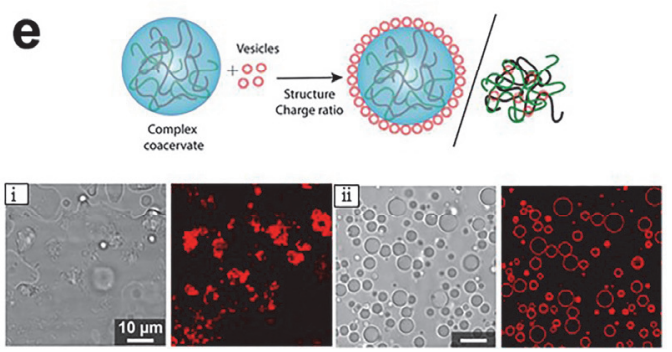

图 5 凝聚体人造细胞的个体功能. (a)核酶对底物的催化裂解反应: (a1)锤头状核酶的碱基序列, (a2)凝聚层的宽视野光学显微镜图像(左). 在 $t=0$ $\min \left(\right.$ 中)和 $t=900 \mathrm{~min}$ (右)的荧光显微镜图像显示了 $\mathrm{FAM}$ 苂光的增加(参见插图) ${ }^{[127]} ;$ (b) 显示凝聚物的光学显微镜图像, 并且在收集室中储存 1 $\mathrm{h}$ (左)和 $16 \mathrm{~h}$ (右)后的记录. 插图显示了单个凝聚层中 mCherry 表达的相应苂光图像 [121]; (c) 示意图显示了含有叶绿体的具有光合作用的无膜凝聚 物的制备(上), 共聚焦苂光显微镜图像显示了与完整叶绿体分散体混合后的凝聚体(下) ${ }^{[91]}$; (d) 共聚物在凝聚体表面组装成膜的示意图(左图)和苂 光显微镜照片(右图): 插图为三嵌段共聚物的结构式 ${ }^{[68,69]}$; (e)磷脂囊泡在凝聚体表面组装或磷脂囊泡破坏凝聚体结构的示意图(上)和显微镜照片: (i)囊泡破坏凝聚体, (ii)囊泡在凝聚体表面自组装成膜 $[130]$.

Figure 5 Individual functions of coacervates artificial cells. (a) Catalytic cleavage of ribozymes on substrates: (a1) the sequence of hammerhead ribozyme, (a2) Wide-field optical microscopy images of coacervates (left). Fluorescence microscopy images at $t=0$ min (middle) and $t=900 \mathrm{~min}$ (right) show an increase in FAM fluorescence (see inset) ${ }^{[127]}$. Copyright 2018, Springer Nature. (b) Optical microscopy images showing coacervates and recorded $1 \mathrm{~h}$ (left) and $16 \mathrm{~h}$ (right) after storage in the collection chamber. Insets shows corresponding fluorescence images of mCherry expression in single coacervate $^{[121]}$. Copyright 2015 , Royal Society of Chemistry. (c) Scheme showing the preparation of photosynthetically active membrane-free coacervates containing chloroplasts (top), Confocal fluorescence microscopy images showing coacervates after mixing with a dispersion of intact chloroplasts (bottom) ${ }^{[91]}$. Copyright 2018, Royal Society of Chemistry. (d) Schematic illustration of copolymer assembly on the surface of the coacervates to form a film (left) and fluorescence images (right): the inset is the schematic of a bespoke terpolymer ${ }^{[68,69]}$. Copyright 2017 , American Chemical Society. https://pubs.acs.org/doi/full/10.1021/jacs.7b10846. Copyright 2019, American Chemical Society. https://pubs.acs.org/doi/10.1021/acscentsci.9b00345. (e) Schematic illustration of the assembly of phospholipid vesicles on the surface of the coacervates or phospholipid vesicles destroy the coacervates (top) and fluorescence images: (i) the vesicles destroy the coacervates, (ii) the vesicles form a membrane on the surface of the coacervates ${ }^{[130]}$. Copyright 2019 , American Chemical Society. 


\subsection{2 凝聚体人造细胞的群体行为}

生物体是由多种多样的细胞组成的一个高度协调 有序的组织. 通过研究具有群体行为 ${ }^{[97,133-135]}$ 的细胞群 体能够揭示生命系统维系复杂秩序的奥秘, 因此研究具 有群体行为的凝聚体也具有重要意义. 比如细胞群之间 信号分子的传递、吞噬细胞的吞噬功能以及形成组织结 构等.

生物系统时刻处于动态的过程中, 非稳定状态是其 中重要的状态. Yin 等 ${ }^{[87,88]}$ 通过均匀电场刺激凝聚体液 滴, 导致液滴的不稳定性. 在电场强度 $10 \sim 20 \mathrm{~V} \cdot \mathrm{cm}^{-1}$ 时, 液滴能够保持稳定; 但当电场强度提高到 $30 \sim 40$ $\mathrm{V} \cdot \mathrm{cm}^{-1}$ 时, 液滴内部随机出现小的隔室; 当电场强度提 高到 $50 \mathrm{~V} \cdot \mathrm{cm}^{-1}$ 以上时, 形成的小隔室开始生长并持续 存在; 再增加到 $70 \mathrm{~V} \cdot \mathrm{cm}^{-1}$ 时, 结构和形态的波动非常 强烈, 并有液滴喷出现象出现(图 6a). 该研究为动态人 造细胞群体的研究提供了启示.

信号传递 ${ }^{[136]}$ 是细胞内重要的生物过程之一, 而阵 列结构可以作为研究信号传递过程中的重要手段. 目 前, 在以凝聚体为基础的阵列的构建中, 比较突出的工 作为声场阵列 ${ }^{[137-139]}$. Tian 等 ${ }^{[137]}$ 实现了凝聚体人造细胞 在声场中自发组装成周期性二维阵列的排布, 阵列中凝 聚体液滴大小均一且间距可控. 该阵列在有反应物扩散 梯度时显示出随时间和空间变化的传递现象(图 6b), 说 明距离会影响群体信息传输. 另外作者制备了三种含有 不同苂光标记酶的阵列, 加入酶的底物使其扩散, 三种 底物由于具有不同的扩散速率使得酶反应的应答具有 不同效率.

a
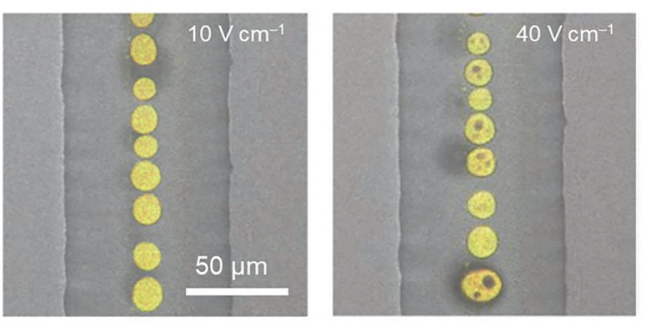

b
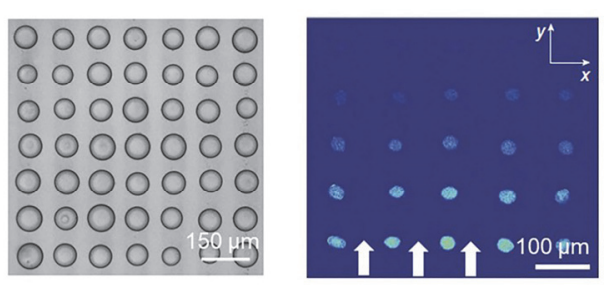
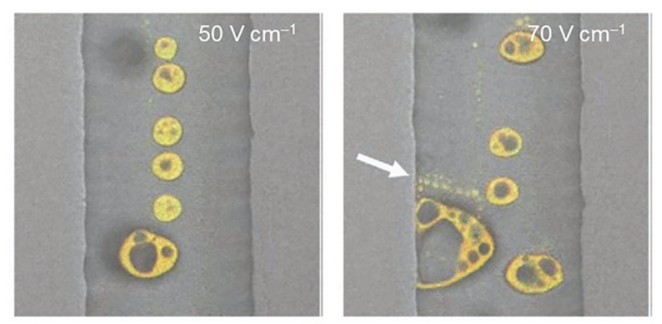

主客体细胞间的相互作用，是生物群体之间重要的 作用模式. Martin 等 ${ }^{[140]}$ 将脂肪酸凝聚体与蛋白质体构建 成多隔室的人造细胞模型，利用客体分子的拮抗作用使 复合结构打乱重组形成蛋白质体包含囊泡的复合结构 (图 6c). 蛋白质体作为客体细胞内部包裹葡萄糖氧化酶 $(\mathrm{GOx})$ 被内化到装载有辣根过氧化物酶(HRP)的 $\mathrm{pH}$ 响应 型脂肪酸凝聚体中. 当溶液中存在葡萄糖时, 蛋白质体 会与脂肪酸凝聚体协同作用, 经途径 1 生成绿色苂光的 2,3-二氨基吩嗪( $o-\mathrm{PD})$. 此外蛋白质体会经途径 2 生成 葡萄糖内酯(GDL), 使体系 $\mathrm{pH}$ 降低, 导致凝聚体液滴分 解变成囊泡, 被包埋的蛋白质体释放. 这种多隔室的可 自我重组的宿主-客体分子的复杂人造细胞模型, 为发 展具有协同和拮抗相互作用模式的人造细胞群提供了 研究基础. 吞噬细胞的吞噬行为, 是另外一种重要的细 胞间作用模式. Qiao 等 ${ }^{[70]}$ 发现凝聚体会使蛋白质体分 解. 凝聚体通过静电相互作用攻击蛋白质体，由于该凝 聚体本身富集了蛋白酶 $\mathrm{K}$, 可裂解蛋白质体, 使蛋白质 体内部负载的葡聚糖或双链 DNA 等物质被释放然后被 凝聚体吸收, 最终蛋白质体完全裂解, 凝聚体逃离. 这 个过程体现了凝聚体对蛋白质体的一种吞噬和掠夺行 为, 提供了互动人工原生细胞群落的模型. 此外 Qiao 等 ${ }^{[141]}$ 将主客体作用与吞噬行为结合研究了凝聚体与蛋 白质体间作用. 更进一步, Zhang 等 ${ }^{[142]}$ 研究了凝聚体引 发的真实细胞的入侵防御机制.

此外在人造组织模拟方面，凝聚体本身容易发生聚 集而使体积不断增大, 可以通过界面自组装维持凝聚体 的稳定性. Liu 等 ${ }^{[143]}$ 用水凝胶将凝聚体固定, 形成了组

\section{C}

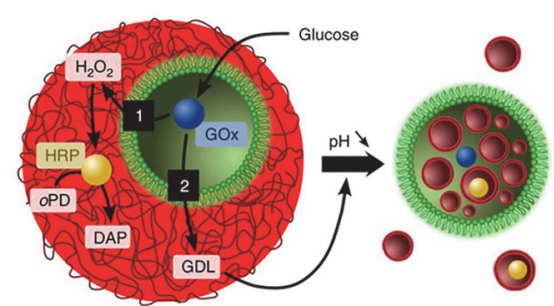

图 6 凝聚体的群体行为. (a) 凝聚体人造细胞在不同强度电场作用下的显微镜图像 ${ }^{[87]}$; (b)声场下凝聚体阵列(左)及酶分子在阵列中的传递(右)的显 微镜照片 ${ }^{[137]}$; (c)合成宿主-客体人造细胞的协同和拮抗行为的示意图 ${ }^{[140]}$.

Figure 6 Collective behaviors of coacervates. (a) Microscope images of coacervate-based artificial cells under different electric fields ${ }^{[87]}$. Copyright 2016, Springer Nature. (b) Acoustic patterning of coacervates micro-droplet arrays (left) and the fluorescence microscopy image of transferring of enzyme molecules in the array (right) ${ }^{[137]}$. Copyright 2018, Springer Nature. (c) Schematic showing synergistic and antagonistic behaviour in synthetic host-guest artificial cells ${ }^{[140]}$. Copyright 2016, Springer Nature. 
织化模块; 并且还在水凝胶模块间实现了 DNA 酶介导 的级联反应，构建了类似组织结构的人造组织.

凝聚体作为人造细胞模型, 在细胞群体行为的模拟 方面已经取得一定成果, 如信号传递与吞噬作用等, 但 相关的研究仍然处于十分初级的阶段, 对于其他同样重 要的群体行为比如趋化性等的研究仍未有报道.

表 2 总结了凝聚体作为细胞器、人造细胞以及群体 行为的制备方法、应用和未来的发展方向. 凝聚体作为 人造细胞器和人造细胞在人造细胞领域的研究处于初 步探索阶段. 目前将凝聚体作为细胞器的制备方法较 少, 应用也多是酶催化反应, 仿生功能方面仍然还有较 大的空白. 凝聚体作为人造细胞的研究目前主要是实现 了部分 RNA 的催化功能, 而更加复杂的生化过程仍然 难以实现. 同时, 生物体的群体行为更为复杂, 用凝聚 体群进行模拟工作还具有很大的探索空间, 比如模拟细 菌群落的趋化性.

\section{4 总结与展望}

主要依赖静电相互作用所形成的复合凝聚体, 可以 对部分物质进行富集而实现该物质在溶液和凝聚体内 的差异性分配, 其稳定性受多种环境因素如 $\mathrm{pH}$ 值、温 度等调节. 这种简单的模型被认为是原始地球环境下最 初的细胞结构, 因此受到了广泛关注.

凝聚体在模拟人造细胞器方面展现出了非常广泛 的应用前景. 最近在细胞内发现了多种 LLPS 导致的亚
隔室结构, 它们对于细胞内的生化反应具有重要作用. 因此将这类结构作为人造细胞器的研究得到了广泛重 视. 研究者们在人造细胞内可以通过外环境 $\mathrm{pH}$ 、温度等 条件的改变在内部形成凝聚体，同时也赋予了凝聚体作 为细胞器的生理功能, 如转录 ${ }^{[48]}$ 等, 在真实细胞中也通 过光刺激的方法实现了凝聚体人造细胞器的形成 ${ }^{[99,100]}$. 然而, 细胞内的胞质环境和一般的水溶液有很大的差 距，它是一个高度拥挤的环境 ${ }^{[144,145]}$. 在这种拥挤环境 下构建的凝聚体细胞器应该能够更好地模拟生理条件 下凝聚体的功能. 与此同时，当前基于凝聚体的人造细 胞器内部的反应大多都十分简单，一些更加复杂且具有 重要意义的反应应该在凝聚体人造细胞内重构, 如能量 供应、代谢等.

作为原始细胞模型, 凝聚体在人造细胞领域受到广 泛重视. 目前, 已经在单个凝聚体内提高了 RNA 酶的 催化活性, 用其包裹叶绿体实现了光反应等重要的生化 反应. 将很多种外壳结构组装到凝聚体表面以克服凝聚 体的不稳定性. 凝聚体的群体行为研究刚刚兴起. 凝聚 体内部的反应可以对凝聚体的分裂产生影响 ${ }^{[146,147]}$, 并 且可以改变凝聚体的形状 ${ }^{[148]}$, 这可以模拟真实细胞的 复制过程. 以此为基础, 研究凝聚体的生长分裂过程来 模拟真实细胞的复制过程, 能够完善凝聚体人造细胞的 功能. 除了复制之外, 真实细胞中重要的生化反应过程 还包括适应性、运动等, 这些功能在凝聚体内的实现也 可以完善凝聚体人造细胞的体系. 除此之外, 无膜凝聚

表 2 凝聚体在人造细胞领域的应用

Table 2 Applications of coacervates in the field of artificial cells

\begin{tabular}{|c|c|c|c|c|c|}
\hline \multicolumn{2}{|c|}{ 研究内容 } & 制备方法 & 已有应用 & 潜在应用 & 发展方向 \\
\hline \multicolumn{2}{|c|}{$\begin{array}{c}\text { 凝聚体作为 } \\
\text { 细胞器 }\end{array}$} & $\begin{array}{l}\text { (1)微流控水油分离得到囊泡包 } \\
\text { 凝聚体结构; } \\
\text { (2)囊泡中有一种凝聚体原料, } \\
\text { 再通过 } \alpha \text {-溶血素在膜上打孔使 } \\
\text { 另一种小分子原料进入生成凝 } \\
\text { 聚体; } \\
\text { (3)制备囊泡的同时包进去凝聚 } \\
\text { 体的两种原料. }\end{array}$ & $\begin{array}{l}\text { (1)在细胞中合成凝聚体原料进而生成凝聚 } \\
\text { 体; } \\
\text { (2)在细胞器中实现转录反应、翻译; } \\
\text { (3)通过温度、 } \mathrm{pH} \text { 可逆调整凝聚体的生成与 } \\
\text { 解离, 作为酶反应的开关; } \\
\text { (4)光刺激真实细胞蛋白发生自凝聚生成凝 } \\
\text { 聚体. }\end{array}$ & $\begin{array}{l}\text { 行使多种细胞 } \\
\text { 器功能, 如吞 } \\
\text { 噬分解有害物 } \\
\text { 质 }\end{array}$ & $\begin{array}{l}\text { (1)开发更多简便可 } \\
\text { 行的制备方法; } \\
\text { (2)研究的体外生化 } \\
\text { 过程要强调与真实 } \\
\text { 生物体的相关性 }\end{array}$ \\
\hline \multirow[b]{2}{*}{$\begin{array}{c}\text { 凝聚体作 } \\
\text { 为人造 } \\
\text { 细胞 }\end{array}$} & $\begin{array}{l}\text { 人造 } \\
\text { 细胞 } \\
\text { 个体 } \\
\text { 功能 }\end{array}$ & 一定浓度和比例下简单混合 & $\begin{array}{l}\text { (1) RNA(核酶)催化底物裂解; } \\
\text { (2)遗传物质的转录和翻译; } \\
\text { (3)凝聚体吸收真实细胞器叶绿体, 构建仿生 } \\
\text { 功能的人造细胞. }\end{array}$ & $\begin{array}{l}\text { (1)凝聚体原料 } \\
\text { 的不同对生化 } \\
\text { 反应速率的影 } \\
\text { 响; } \\
\text { (2)抗盐能力强 } \\
\text { 的凝聚体为需 } \\
\text { 要离子参与的 } \\
\text { 酶催化反应提 } \\
\text { 供稳定的场所 }\end{array}$ & 生命起源与进化 \\
\hline & $\begin{array}{l}\text { 人造 } \\
\text { 细胞 } \\
\text { 群体 } \\
\text { 行为 }\end{array}$ & $\begin{array}{l}\text { (1)利用微流控通道约束凝聚体; } \\
\text { (2)利用声场制备凝聚体的阵列; } \\
\text { (3)将凝聚体与其他人造细胞(如 } \\
\text { 蛋白质体)发生相互作用; } \\
\text { (4)水凝胶固定. }\end{array}$ & $\begin{array}{l}\text { (1)电场作用下的凝聚体群体的非稳态行为; } \\
\text { (2)凝聚体阵列中溶质的梯度扩散, 实现群落 } \\
\text { 的信号传输; } \\
\text { (3)凝聚体借助蛋白酶 } \mathrm{K} \text { 吞噬蛋白质体并掠 } \\
\text { 夺其货物, 实现人工细胞群落的演化; } \\
\text { (4)凝聚体与蛋白质体通过生化反应的协同 } \\
\text { 和拮抗作用, 实现细胞的自我重组; } \\
\text { (5)凝聚体与真实细胞间自我防御机制的模 } \\
\text { 拟; } \\
\text { (6)利用水凝胶将凝聚体模块化, 实现组织之 } \\
\text { 间的酶级联反应. }\end{array}$ & $\begin{array}{l}\text { (1)研究细胞间 } \\
\text { 的通讯; } \\
\text { (2)实现群落的 } \\
\text { 演化 }\end{array}$ & $\begin{array}{l}\text { 基于群体的更复杂 } \\
\text { 的仿生行为, 比如与 } \\
\text { 细菌群落的协同生 } \\
\text { 长及趋利避害 }\end{array}$ \\
\hline
\end{tabular}


体的外壳可以赋予凝聚体更加丰富的功能, 对于凝聚体 外壳的研究也十分重要. 关于以凝聚体为基础的人造细 胞群体行为的研究, 除了目前实现的吞噬行为、信号传 递外, 还可以研究其群体分化行为 ${ }^{[31]}$ 、群体的趋化性等 方面.

最新发现的多相凝聚体是一种多层结构, 可以作为 内部包含了凝聚体细胞器的凝聚体人造细胞. 这种结构 与真实细胞状态最为接近, 与其他复合人造细胞体系相 比, 该体系还具有很多优势, 如物质在不同凝聚相中的 差异性分配, 良好的动态特性等. 这些优点使多相凝聚 体成为未来凝聚体人造细胞系统的重要研究内容之一.

总之, 以凝聚体为基础的人造细胞研究已经成为合 成生物学中的重要研究方向, 该研究领域仍然存在很多 未解决的问题，充满了挑战和机遇.

\section{作者简介}

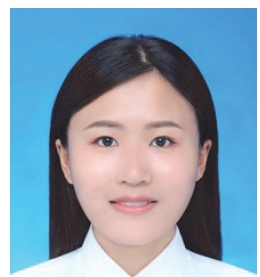

间琳, 硕士研究生, 2018 年毕业于济南大学, 获理学学士 学位. 2018 年起于哈尔滨工业大学化工与化学学院攻读硕士 学位. 目前主要研究方向为凝聚体及其在人造细胞领域的应 用.

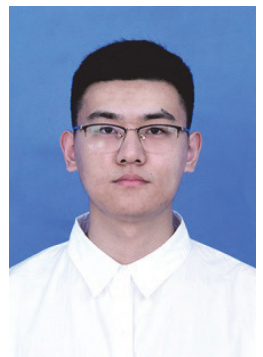

任永硕, 博士研究生. 2019 年毕业于哈尔滨工业大学, 获 工学学士学位. 2019 年起于哈尔滨工业大学攻读博士学位. 目 前主要研究方向为人造细胞的磁控阵列的构建及基于磷脂合 成的可持续生长分裂的人造细胞体系的研究.

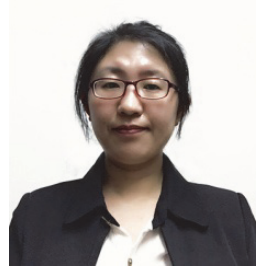

王雪靖, 博士后. 2019 年毕业于哈尔滨工业大学, 获得工 学博士学位. 研究方向为功能化磷脂囊泡及磷脂囊泡阵列的 构建, 以及磷脂囊泡在人造细胞领域的应用.

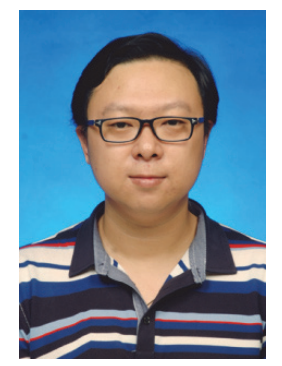

穆韚, 讲师, 硕士生导师, 哈尔滨工业大学化工与化学学 院生物分子与化学工程系老师. 先后主持承担国家自然科学 基金项目等项目。迄今发表 SCI 文章 20 余篇，主要研究方向 包括人造细胞、污染物监测与降解等.

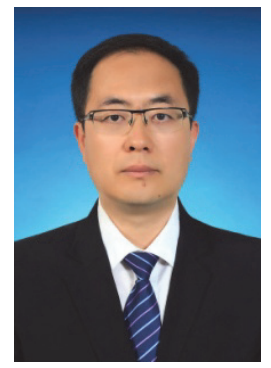

韩晓军, 教授, 博士生导师, 英国皇家化学会会士, 哈尔 滨工业大学化工与化学学院生物分子与化学工程系主任. 主 持承担国家自然科学基金等基金项目 20 多项。迄今在 Nat. Commun., Adv. Mater., J. Am. Chem. Soc. 等刊物上发表 SCI 论 文 160 多篇. 目前主要研究方向包括人造细胞、药物控释等.

\section{References}

[1] Nakashima, K. K.; Vibhute, M. A.; Spruijt, E. Front. Mol. Biosci. 2019, 6,1 .

[2] Lau, H. K.; Paul, A.; Sidhu, I.; Li, L.; Sabanayagam, C. R.; Parekh, S. H.; Kiick, K. L. Adv. Sci. 2018, 5, 1701010

[3] Kizilay, E.; Kayitmazer, A. B.; Dubin, P. L. Adv. Colloid Interface Sci. 2011, 167, 24.

[4] Bungenberg De Jong, H. G. Ned. Tijdschr. Geneeskd. 1952, 96, 1489 .

[5] Kerfeld, C. A.; Heinhorst, S.; Cannon, G. C. Annu. Rev. Microbiol. 2010, 64, 391.

[6] Alberti, S. J. Cell Sci. 2017, 130, 2789.

[7] Gabaldon, T.; Pittis, A. A. Biochimie 2015, 119, 262.

[8] Heald, R.; Cohen-Fix, O. Curr. Opin. Cell Biol. 2014, 26, 79

[9] Sirri, V.; Urcuqui-Inchima, S.; Roussel, P.; Hernandez-Verdun, D. Histochem. Cell Biol. 2008, 129, 13.

[10] Crowe, C. D.; Keating, C. D. Interface Focus 2018, 8, 20180032.

[11] Aumiller, W. M., Jr.; Davis, B. W.; Keating, C. D. Int. Rev. Cell Mol. Biol. 2014, 307, 109.

[12] Shin, Y.; Brangwynne, C. P. Science 2017, 357, eaaf4382.

[13] Banani, S. F.; Lee, H. O.; Hyman, A. A.; Rosen, M. K. Nat. Rev. Mol. Cell Biol. 2017, 18, 285.

[14] Boisvert, F. M.; van Koningsbruggen, S.; Navascues, J.; Lamond, A. I. Nat. Rev. Mol. Cell Biol. 2007, 8, 574

[15] Gall, J. G. Nat. Rev. Mol. Cell Biol. 2003, 4, 975.

[16] Jain, S.; Wheeler, J. R.; Walters, R. W.; Agrawal, A.; Barsic, A.; Parker, R. Cell 2016, 164, 487.

[17] Brangwynne, C. P.; Eckmann, C. R.; Courson, D. S.; Rybarska, A.; Hoege, C.; Gharakhani, J.; Julicher, F.; Hyman, A. A. Science 2009, $324,1729$.

[18] Iwashita, K.; Handa, A.; Shiraki, K. Int. J. Biol. Macromol. 2018, 120,10 .

[19] Franzmann, T. M.; Jahnel, M.; Pozniakovsky, A.; Mahamid, J.; Holehouse, A. S.; Nuske, E.; Richter, D.; Baumeister, W.; Grill, S. W.; Pappu, R. V.; Hyman, A. A.; Alberti, S. Science 2018, 359, eaao5654. 
[20] Anderson, P.; Kedersha, N. Trends Biochem. Sci. 2008, 33, 141.

[21] French, J. B.; Jones, S. A.; Deng, H. Y.; Pedley, A. M.; Kim, D.; Chan, C. Y.; Hu, H. B.; Pugh, R. J.; Zhao, H.; Zhang, Y. X.; Huang, T. J.; Fang, Y.; Zhuang, X. W.; Benkovic, S. J. Science 2016, 351, 733.

[22] Alberti, S.; Gladfelter, A.; Mittag, T. Cell 2019, 176, 419.

[23] Lentini, R.; Yeh Martin, N.; Mansy, S. S. Curr. Opin. Chem. Biol. 2016, 34, 53 .

[24] Aufinger, L.; Simmel, F. C. Chem. Eur. J. 2019, 25, 12659.

[25] Engelhart, A. E.; Adamala, K. P.; Szostak, J. W. Nat. Chem. 2016, 8, 448 .

[26] Budin, I.; Debnath, A.; Szostak, J. W. J. Am. Chem. Soc. 2012, 134, 20812.

[27] Zong, W.; Ma, S. H.; Zhang, X. N.; Wang, X. J.; Li, Q. C.; Han, X. J. J. Am. Chem. Soc. 2017, 139, 9955.

[28] Zong, W.; Zhang, X. N.; Li, C.; Han, X. J. ACS Synth. Biol. 2018, 7, 945.

[29] Li, S. B.; Wang, X. J.; Mu, W.; Han, X. J. Anal. Chem. 2019, 91, 6859.

[30] Kamiya, K.; Takeuchi, S. J. Mat. Chem. B 2017, 5, 5911.

[31] Dupin, A.; Simmel, F. C. Nat. Chem. 2019, 11, 32.

[32] van Swaay, D.; deMello, A. Lab Chip 2013, 13, 752.

[33] Li, Q. C.; Wang, X. J.; Ma, S. H.; Zhang, Y.; Han, X. J. Colloids Surf. B-Biointerfaces 2016, 147, 368.

[34] Tian, W.; Sasaki, Y.; Ikeda, A.; Kikuchi, J.; Song, X.; Fan, S. Acta Chim. Sinica 2004, 62, 1230 (in Chinese). (田文杰, 佐佐木善浩, 池田笃志, 菊池纯一, 宋溪明, 范圣第, 化学学报, 2004, 62, 1230.)

[35] Li, L.; Lin, M.; Qiu, F.; Yang, Y. Acta Chim. Sinica 2005, 63, 1375 (in Chinese). (李莉, 林美玉, 邱枫, 杨玉良, 化学学报, 2005, 63, 1375.)

[36] Meng, F. H.; Zhong, Z. Y. J. Phys. Chem. Lett. 2011, 2, 1533.

[37] LoPresti, C.; Lomas, H.; Massignani, M.; Smart, T.; Battaglia, G. J. Mater. Chem. 2009, 19, 3576.

[38] Oparin, A. I. Origin of Life, Dover Publications, New York, 1953.

[39] Poudyal, R. R.; Pir Cakmak, F.; Keating, C. D.; Bevilacqua, P. C. Biochemistry 2018, 57, 2509.

[40] Overbeek, J. T.; Voorn, M. J. J. Cell. Physiol. 1957, 49, 7.

[41] Kim, S.; Huang, J.; Lee, Y.; Dutta, S.; Yoo, H. Y.; Jung, Y. M.; Jho, Y.; Zeng, H.; Hwang, D. S. Proc. Natl. Acad. Sci. 2016, 113, E847.

[42] Hoffmann, K. Q.; Perry, S. L.; Leon, L.; Priftis, D.; Tirrell, M.; de Pablo, J. J. Soft Matter 2015, 11, 1525.

[43] Roy, D.; Brooks, W. L. A.; Sumerlin, B. S. Chem. Soc. Rev. 2013, 42,7214 .

[44] Blocher, W. C.; Perry, S. L. Wiley Interdiscip. Rev.: Nanomed. Nanobiotechnol. 2017, 9, e1442.

[45] Priftis, D.; Xia, X.; Margossian, K. O.; Perry, S. L.; Leon, L.; Qin, J.; de Pablo, J. J.; Tirrell, M. Macromolecules 2014, 47, 3076.

[46] Jeon, B. J.; Nguyen, D. T.; Abraham, G. R.; Conrad, N.; Fygenson, D. K.; Saleh, O. A. Soft Matter 2018, 14, 7009.

[47] Schuster, B. S.; Reed, E. H.; Parthasarathy, R.; Jahnke, C. N.; Caldwell, R. M.; Bermudez, J. G.; Ramage, H.; Good, M. C.; Hammer, D. A. Nat. Commun. 2018, 9, 12.

[48] Deng, N.-N.; Huck W. T. S. Angew. Chem. Int. Ed. 2017, 56, 9736.

[49] Koga, S.; Williams, D. S.; Perriman, A. W.; Mann, S. Nat. Chem. 2011, 3, 720.

[50] Black, K. A.; Priftis, D.; Perry, S. L.; Yip, J.; Byun, W. Y.; Tirrell, M. ACS Macro Lett. 2014, 3, 1088.

[51] Aumiller, W. M., Jr.; Keating, C. D. Nat. Chem. 2016, 8, 129.

[52] Spruijt, E.; Sprakel, J.; Stuart, M. A. C.; van der Gucht, J. Soft Matter 2010, 6, 172

[53] Frankel, E. A.; Bevilacqua, P. C.; Keating, C. D. Langmuir 2016, 32, 2041.

[54] Zhao, M. M.; Zacharia, N. S. J. Chem. Phys. 2018, 149, 163326.

[55] Lindhoud, S.; Claessens, M. M. A. E. Soft Matter 2016, 12, 408.

[56] Obermeyer, A. C.; Mills, C. E.; Dong, X. H.; Flores, R. J.; Olsen, B. D. Soft Matter 2016, 12, 3570 .

[57] Kapelner, R. A.; Obermeyer, A. C. Chem. Sci. 2019, 10, 2700.

[58] Cummings, C. S.; Obermeyer, A. C. Biochemistry 2018, 57, 314.

[59] Horn, J. M.; Kapelner, R. A.; Obermeyer, A. C. Polymers 2019, 11, 578.

[60] Pathak, J.; Rawat, K. RSC Adv. 2015, 5, 67066

[61] Pathak, J.; Rawat, K. J. Phys. Chem. B 2014, 118, 11161.

[62] Perry, S. L.; Leon, L.; Hoffmann, K. Q.; Kade, M. J.; Priftis, D.; Black, K. A.; Wong, D.; Klein, R. A.; Pierce, C. F.; Margossian, K.
O.; Whitmer, J. K.; Qin, J.; de Pablo, J. J.; Tirrell, M. Nat. Commun. $\mathbf{2 0 1 5}, 6,8$.

[63] Aumiller, W. M., Jr.; Keating, C. D. Adv. Colloid Interface Sci. 2017, $239,75$.

[64] Souza, C. J. F.; da Costa, A. R.; Souza, C. F.; Tosin, F. F. S.; Garcia-Rojas, E. E. Int. J. Biol. Macromol. 2018, 107, 1253.

[65] Souza, C. J. F.; Garcia-Rojas, E. E. Food Hydrocoll. 2015, 47, 124.

[66] Hwang, D. S.; Zeng, H. B.; Srivastava, A.; Krogstad, D. V.; Tirrell, M.; Israelachvili, J. N.; Waite, J. H. Soft Matter 2010, 6, 3232.

[67] Zhang, X. M.; Lin, Y. X.; Eschmann, N. A.; Zhou, H. J.; Rauch, J. N.; Hernandez, I.; Guzman, E.; Kosik, K. S.; Han, S. I. PLoS Biol. 2017, 15, 28

[68] Mason, A. F.; Buddingh, B. C.; Williams, D. S.; van Hest, J. C. M. J. Am. Chem. Soc. 2017, 139, 17309.

[69] Mason, A. F.; Yewdall, N. A.; Welzen, P. L. W.; Shao, J.; van Stevendaal, M.; van Hest, J. C. M.; Williams, D. S.; Abdelmohsen, L. ACS Cent. Sci. 2019, 5, 1360.

[70] Qiao, Y.; Li, M.; Booth, R.; Mann, S. Nat. Chem. 2017, 9, 110.

[71] Dora Tang, T. Y.; Rohaida Che Hak, C.; Thompson, A. J.; Kuimova, M. K.; Williams, D. S.; Perriman, A. W.; Mann, S. Nat. Chem. 2014, 6, 527.

[72] Priftis, D.; Farina, R.; Tirrell, M. Langmuir 2012, $28,8721$.

[73] Lu, T.; Spruijt, E. J. Am. Chem. Soc. 2020, 142, 2905.

[74] Ulijn, R. V.; Lampel, A. Isr. J. Chem. 2019, 1.

[75] Choi, J.-M.; Wang, J.; Holehouse, A. S.; Alberti, S.; Hyman, A. A.; Pappu, R. V. Biophys. J. 2018, 114, 561A

[76] Wei, M.-T.; Elbaum-Garfinkle, S.; Holehouse, A. S.; Chen, C. C.-H.; Feric, M.; Arnold, C. B.; Priestley, R. D.; Pappu, R. V.; Brangwynne, C. P. Nat. Chem. 2017, 9, 1118.

[77] Oldfield, C. J.; Dunker, A. K. Annu. Rev. Biochem. 2014, 83, 553.

[78] Cohan, M. C.; Posey, A. E.; Mittal, A.; Grigsby, S. J.; Holehouse, A. S.; Buske, P. J.; Levin, P. A.; Pappu, R. V. Mol. Biol. Cell 2017, 114, 590A.

[79] Harmon, T. S.; Holehouse, A. S.; Pappu, R. V. New J. Phys. 2018, 20, 045002

[80] Ruff, K. M.; Pappu, R. V.; Holehouse, A. S. Curr. Opin. Struct. Biol. $\mathbf{2 0 1 9}, 56,1$.

[81] Molliex, A.; Temirov, J.; Lee, J.; Coughlin, M.; Kanagaraj, A. P.; Kim, H. J.; Mittag, T.; Taylor, J. P. Cell 2015, 163, 123.

[82] Elbaum-Garfinkle, S.; Kim, Y.; Szczepaniak, K.; Chen, C. C. H.; Eckmann, C. R.; Myong, S.; Brangwynne, C. P. Proc. Natl. Acad. Sci. 2015, 112, 7189 .

[83] Tan, Y. P.; Hoon, S.; Guerette, P. A.; Wei, W.; Ghadban, A.; Hao, C.; Miserez, A.; Waite, J. H. Nat. Chem. Biol. 2015, 11, 488.

[84] Madinya, J. J.; Chang, L. W.; Perry, S. L.; Sing, C. E. Mol. Syst. Des. Eng. 2020, 5, 632.

[85] Mountain, G. A.; Keating, C. D. Biomacromolecules 2020, 21, 630.

[86] Jing, H.; Bai, Q.; Lin, Y. n.; Chang, H.; Yin, D.; Liang, D. Langmuir 2020, 36, 8017.

[87] Yin, Y. D.; Niu, L.; Zhu, X. C.; Zhao, M. P.; Zhang, Z. X.; Mann, S.; Liang, D. H. Nat. Commun. 2016, 7, 7.

[88] Yin, Y. D.; Chang, H. J.; Jing, H. R.; Zhang, Z. X.; Yan, D. D.; Mann, S.; Liang, D. H. Soft Matter 2018, 14, 6514

[89] Fothergill, J.; Li, M.; Davis, S. A.; Cunningham, J. A.; Mann, S. Langmuir 2014, 30, 14591.

[90] Dompe, M.; Cedano-Serrano, F. J.; Heckert, O.; van den Heuvel, N.; van der Gucht, J.; Tran, Y.; Hourdet, D.; Creton, C.; Kamperman, M. Adv. Mater. 2019, 31, e1808179.

[91] Kumar, B.; Fothergill, J.; Bretherton, J.; Tian, L. F.; Patil, A. J.; Davis, S. A.; Mann, S. Chem. Commun. 2018, 54, 3594.

[92] Lawrence, M. S.; Phillips, K. J.; Liu, D. R. J. Am. Chem. Soc. 2007, 129,10110

[93] Comert, F.; Malanowski, A. J.; Azarikia, F.; Dubin, P. L. Soft Matter 2016, 12, 4154

[94] Comert, F.; Xu, A. Y.; Madro, S. P.; Liadinskaia, V.; Dubin, P. L. J. Chem. Phys. 2018, 149, 163321.

[95] Xu, A. Y.; Melton, L. D.; Ryan, T. M.; Mata, J. P.; Rekas, A.; Williams, M. A. K.; McGillivray, D. J. Food Hydrocoll. 2018, 77, 952.

[96] Pandey, P. K.; Kaushik, P.; Rawat, K.; Aswal, V. K.; Bohidar, H. B. Soft Matter 2017, 13, 6784.

[97] Lin, Y.; Jing, H.; Liu, Z.; Chen, J.; Liang, D. Langmuir 2020, 36, 1709.

[98] Simon, J. R.; Carroll, N. J.; Rubinstein, M.; Chilkoti, A.; Lopez, G. P. Nat. Chem. 2017, 9, 509. 
[99] Reed, E. H.; Schuster, B. S. ACS Synth. Biol. 2020, 9, 500.

[100] Shin, Y.; Berry, J.; Pannucci, N.; Haataja, M. P.; Toettcher, J. E.; Brangwynne, C. P. Cell 2017, 168, 159.

[101] Mitrea, D. M.; Kriwacki, R. W. Cell Commun. Signaling 2016, 14, R1097.

[102] Bayley, H.; Mason, A. F.; van Hest, J. C. M. Emerging Top. Life Sci. 2019, 3, 567.

[103] Ghellab, S. E.; Li, Q. C.; Fuhs, T.; Bi, H. M.; Han, X. J. Colloid Surf. B-Biointerfaces 2017, 160, 697.

[104] Spoelstra, W. K.; Deshpande, S.; Dekker, C. Curr. Opin. Biotechnol. 2018, 51, 47.

[105] Blain, J. C.; Szostak, J. W. Annu. Rev. Biochem. 2014, 83, 615.

[106] Vance, J. E. Traffic 2015, 16, 1.

[107] Zhang, Y. M.; Rock, C. O. Nat. Rev. Microbiol. 2008, 6, 222.

[108] Hansen, J. S.; Elbing, K.; Thompson, J. R.; Malmstadt, N.; Lindkvist-Petersson, K. Chem. Commun. 2015, 51, 2316.

[109] Nordlund, G.; Brzezinski, P.; von Ballmoos, C. Nat. Commun. 2014, 5,8 .

[110] Lee, K. Y.; Park, S. J.; Lee, K. A.; Kim, S. H.; Kim, H.; Meroz, Y.; Mahadevan, L.; Jung, K. H.; Ahn, T. K.; Parker, K. K.; Shin, K. Nat. Biotechnol. 2018, 36, 530.

[111] Sokolova, E.; Spruijt, E.; Hansen, M. M. K.; Dubuc, E.; Groen, J.; Chokkalingam, V.; Piruska, A.; Heus, H. A.; Huck, W. T. S. Proc. Natl. Acad. Sci. 2013, 110, 11692.

[112] Booth, R.; Qiao, Y.; Li, M.; Mann, S. Angew. Chem. Int. Ed. 2019, 3, 1.

[113] Last, M. G. F.; Deshpande, S.; Dekker, C. ACS Nano 2020, 14, 4487.

[114] Sato, Y.; Takinoue, M. Micromachines 2019, 10, 216.

[115] Linsenmeier, M.; Kopp, M. R. G.; Grigolato, F.; Liu, D.; Zuercher, D.; Hondele, M.; Weis, K.; Palmiero, U. C.; Arosio, P. Angew. Chem. Int. Ed. 2019, 58, 14489.

[116] Love, C.; Steinkuhler, J.; Gonzales, D. T.; Yandrapalli, N.; Robinson, T.; Dimova, R.; Tang, T. D. Angew. Chem. Int. Ed. 2020, 59, 5950.

[117] Deshpande, S.; Brandenburg, F.; Lau, A.; Last, M. G. F.; Spoelstra, W. K.; Reese, L.; Wunnava, S.; Dogterom, M.; Dekker, C. Nat. Commun. 2019, 10, 1800.

[118] Shin, Y.; Berry, J.; Pannucci, N.; Haataja, M. P.; Toettcher, J. E.; Brangwynne, C. P. Cell 2017, 168, 159.

[119] Yewdall, N. A.; Mason, A. F.; van Hest, J. C. M. Interface Focus 2018, 8, 15.

[120] Zwicker, D.; Seyboldt, R.; Weber, C. A.; Hyman, A. A.; Jülicher, F. Nat. Phys. 2016, 13, 408 .

[121] Tang, T. Y. D.; van Swaay, D.; deMello, A.; Anderson, J. L. R.; Mann, S. Chem. Commun. 2015, 51, 11429.

[122] Deng, N.-N.; Vibhute, M. A.; Zheng, L.; Zhao, H.; Yelleswarapu, M.; Huck, W. T. S. J. Am. Chem. Soc. 2018, 140, 7399.

[123] Krishna Kumar, R.; Yu, X.; Patil, A. J.; Li, M.; Mann, S. Angew. Chem. Int. Ed. 2011, 50, 9343.
[124] Dzieciol, A. J.; Mann, S. Chem. Soc. Rev. 2012, 41, 79.

[125] Chatterjee, S.; Yadav, S. Life 2019, 9, 1.

[126] Strulson, C. A.; Molden, R. C.; Keating, C. D.; Bevilacqua, P. C. Nat. Chem. 2012, 4, 941.

[127] Drobot, B.; Iglesias-Artola, J. M.; Le Vay, K.; Mayr, V.; Kar, M.; Kreysing, M.; Mutschler, H.; Tang, T. D. Nat. Commun. 2018, 9, 3643.

[128] Poudyal, R. R.; Guth-Metzler, R. M.; Veenis, A. J.; Frankel, E. A.; Keating, C. D.; Bevilacqua, P. C. Nat. Commun. 2019, 10, 490.

[129] Tang, T. Y. D.; Antognozzi, M.; Vicary, J. A.; Perriman, A. W.; Mann, S. Soft Matter 2013, 9, 7647.

[130] Pir Cakmak, F.; Grigas, A. T.; Keating, C. D. Langmuir 2019, 35, 7830.

[131] Martin, N.; Douliez, J. P. Angew. Chem. Int. Ed. 2017, 56, 13689.

[132] Williams, D. S.; Patil, A. J.; Mann, S. Small 2014, 10, 1830.

[133] Byun, C. K.; Hwang, H.; Choi, W. S.; Yaguchi, T.; Park, J.; Kim, D.; Mitchell, R. J.; Kim, T.; Cho, Y. K.; Takayama, S. J. Am. Chem. Soc. 2013, 135, 2242.

[134] Zhu, C. T.; Li, Q. C.; Dong, M. D.; Han, X. J. Anal. Chem. 2018, 90, 14363.

[135] Wang, X. J.; Tian, L. F.; Du, H.; Li, M.; Mu, W.; Drinkwater, B. W.; Han, X. J.; Mann, S. Chem. Sci. 2019, 10, 9446.

[136] Magdalena Estirado, E.; Mason, A. F.; Alemán García, M. Á.; van Hest, J. C. M.; Brunsveld, L. J. Am. Chem. Soc. 2020, $142,9106$.

[137] Tian, L.; Martin, N.; Bassindale, P. G.; Patil, A. J.; Li, M.; Barnes, A.; Drinkwater, B. W.; Mann, S. Nat. Commun. 2016, 7, 13068.

[138] Tian, L. F.; Li, M.; Liu, J. T.; Patil, A. J.; Drinkwater, B. W.; Mann, S. ACS Cent. Sci. 2018, 4, 1551.

[139] Tian, L. F.; Li, M.; Patil, A. J.; Drinkwater, B. W.; Mann, S. Nat. Commun. 2019, 10, 13.

[140] Martin, N.; Douliez, J. P.; Qiao, Y.; Booth, R.; Li, M.; Mann, S. Nat. Commun. 2018, 9, 3652.

[141] Qiao, Y.; Li, M.; Qiu, D.; Mann, S. Angew. Chem. Int. Ed. 2019, 58, 17758.

[142] Zhang, Y. W.; Liu, S. Y.; Yao, Y.; Chen, Y. F.; Zhou, S. H.; Yang, X. H.; Wang, K.; Liu, J. B. Small 2020, 16, 2002073.

[143] Liu, J.; Tian, L.; Mann, S. Angew. Chem. Int. Ed. 2019, 59, 6853.

[144] Zimmerman, S. B.; Harrison, B. Proc. Natl. Acad. Sci. 1987, 84, 1871.

[145] Minton, A. P. J. Cell Sci. 2006, 119, 2863.

[146] te Brinke, E.; Groen, J.; Herrmann, A.; Heus, H. A.; Rivas, G.; Spruijt, E.; Huck, W. T. S. Nat. Nanotechnol. 2018, 13, 849.

[147] Zwicker, D.; Seyboldt, R.; Weber, C. A.; Hyman, A. A.; Julicher, F. Nat. Phys. 2017, 13, 408.

[148] Spoelstra, W. K.; van der Sluis, E. O.; Dogterom, M.; Reese, L. Langmuir 2020, 36, 1956. 